\title{
Selecting the Best? Spillover and Shadows in Elimination Tournaments
}

\author{
June 2013
}

\begin{abstract}
We consider how past, current, and future competition within an elimination tournament affect the likelihood of selecting the stronger player as the winner. We present a two-stage model that yields the following main results: (1) a shadow effect - the stronger the expected future competitor, the lower the probability that the stronger player wins in the current stage and (2) an effort spillover effect-previous effort reduces the probability that the stronger player wins in the current stage. We test our theory predictions using data from high-stakes tournaments. Empirical results suggest that shadow and spillover effects influence match outcomes and have been already been priced into betting markets.
\end{abstract}

Keywords: Elimination tournament, dynamic contest, contest design, effort choice, betting markets. 
Competition for employment and education, innovation funding, and design opportunities can all be framed as multi-stage elimination tournaments in which players are knocked out over successive stages of the event. These contests are often designed to increase player effort - indeed, much of the theoretical and empirical literature focuses on contests as incentive mechanisms. Yet, tournaments may also serve as selection mechanisms, identifying the "best" candidates as overall winners. In labor tournaments where employees' latent talents are not directly observable, firms may organize contests to reveal their workers' relative abilities. ${ }^{1}$ For example, in searching for a CEO, a firm may use a tournament to identify and promote the highest-ability candidate, not simply the one who puts forth the most effort.

In this paper, we study how the strategies of heterogeneous players in match-pair elimination tournaments are shaped by past, current, and future competition. More specifically, we examine how these intertemporal effects influence a tournament's ability to reveal the strongest player as the winner. Negative spillover from past stages may make current effort more costly and depress performance, while the shadow of tough future competition decreases a player's expected future payoffs and may also lead to lower current effort. The differential impact of past and future competition across players in a given match changes the effectiveness of tournaments as a selection mechanism. We find that both negative spillover and tough future competition increase the probability that a weak candidate wins overall. Our results have practical implications; whether the contest's objective is to encourage effort, select a strong winner, or both, we find evidence suggesting that firms, educators, and other contest designers may need to consider the role of past and future competition in structuring incentives.

In personnel tournaments, workers risk elimination as they advance through corporate management levels. In most contexts, retention of the highest quality worker is most desirable. For example, GE's former CEO, Jack Welch, designed an explicit elimination tournament to select his successor (Konrad 2009). Competition between firms may also be knockout events. In 2010, GE announced a three-stage elimination tournament, the Ecomagination Challenge, to award $\$ 200$ million to the firm that developed the best smart grid technologies. More commonly, architectural firms may compete for large contracts and investment banks may compete for new clients over several elimination stages. Political races also may involve elimination - a candidate must win his party's primary election to compete in the general election to hold office. Many sporting events are also structured as elimination tournaments.

In each of these examples, effort is clearly important; firms want to hire designers, bankers

\footnotetext{
${ }^{1}$ In contrast, Lazear (1986) discusses how performance pay may attract higher quality workers into the firm when the firm cannot readily observe innate worker ability.
} 
and innovators who will invest heavily in the activity at hand, voters want their representatives to work hard on their behalf, and spectators enjoy high action games. However, selection may also be a prime objective of the contest organizer - a client may desire the most creative design firm, voters may value the most skilled politician, and a board may want the smartest executive to lead the company.

We explore elimination tournaments as selection mechanisms with a two-stage matchpair model. One particular strength of our model is that its predictions are framed in terms of outcomes. As a result, they are testable - in contrast with readily observable tournament outcomes, effort is notoriously difficult to measure in the field. We test our theoretical predictions using the outcomes of high-stakes matches; we exploit the random assignment of players in professional tennis tournament draws. Examining the effect of changes in the skill of the expected competitor in the next round, we find strong evidence of a shadow effect. In addition, spillover in tennis tournaments appears to have a particularly negative impact on the stronger player. We also examine tennis betting markets and find that bookmakers' prices reflect both spillover from past competition and the shadow of future opponents.

In early work on knock-out tournaments, Rosen (1986) models a multi-stage contest where players have Tullock-style (1980) contest success functions. Rosen's main result explains the skewed compensation distributions found in many firms - extra rewards are required in late stages of these elimination tournaments to maintain equal levels of effort across stages. Harbaugh and Klumpp (2005) study a special case of Rosen's model with a single prize and where the total supply of effort is fixed across two periods and equal for all players. Because effort is costless in their model, players exhaust all of their remaining effort in the final period. As a result, the weaker player always exerts more effort than the stronger player in the first stage - the stronger player conserves his effort in anticipation of stiff competition in a final stage match against an equally skilled opponent. In this context, "spillover" between stages disadvantages the low-skill players in the final round.

Searls (1963) compares the statistical properties of single- and double-elimination contests and predicts that single-elimination events are most likely to select the highest ability player as the winner. Groh et al. (2008) describe the optimal seeding of heterogeneous players according to the contest designer's objective. Modeling contests as all-pay auctions, they find that common seeding rules that match weakest to strongest players in the semifinals maximize the probability that the strongest player wins overall. Hvide and Kristiansen (2003) study a contest in which competitors' only choice is over their degree of risk taking. They find that the probability that the stronger player wins can be improved by restricting the number and quality of competitors. Ryvkin and Ortmann (2008) and Ryvkin (2010) compare the probability of selection efficiency of three tournament formats when the designer receives 
only a noisy signal of players' abilities and contestants do not choose effort. In contrast, we study players' strategic effort decisions in response to past and future competition.

Ryvkin (2009) considers the elasticities of a player's equilibrium effort with respect to his own ability and the abilities of his opponents across several tournament formats. In elimination tournaments with weakly heterogeneous players, he finds that the abilities of opponents in the more distant future have a lower impact on a player's equilibrium effort than does the ability of the current opponent. Ryvkin also shows that, when players' relative abilities are uniformly distributed, a "balanced" seeding can eliminate the dependence of a player's equilibrium effort on his opponents' abilities. While his work focuses on players' effort, we are particularly concerned with tournament outcomes.

Our effort spillover prediction relates to previous work on fatigue in dynamic competition. Ryvkin (2011) presents a winner-take-all model where homogeneous players face a binary effort decision and effort has no explicit cost - these features are in stark contrast to our model where players are heterogeneous and effort is a continuous and costly choice variable in a multi-prize tournament. In his work, fatigue accumulates across stages and players have no opportunity to refresh their effort resources. Among other results, he finds that equilibrium effort is decreasing in fatigue. Schmitt et al. (2004) study the opposite phenomenonpositive spillover - in rent-seeking contests. They find both theoretical and experimental evidence that positive spillover leads to more first-period expenditure. Our contribution complements and extend these theoretical and experimental results to the field. Moreover, we consider simultaneously the impact of spillover from the past and the shadow of expected future competition.

Sunde (2009) tests the incentive effect of player heterogeneity using data from selected professional tennis tournaments. He finds that heterogeneity impacts the effort choice of the stronger player more than it changes the effort of the weaker player in a match. The effects are not symmetric: for an equal change in rank disparity, the increase in the number of games won by the stronger player is smaller than the decrease in the number of games lost by the weaker player. In contrast to Sunde's work, we study the role of skill heterogeneity across multiple stages of an event - that is, we examine the incentive impact of ability differences with past, current, and (expected) future opponents. The effects of player heterogeneity on effort in one-shot tournaments has been studied both theoretically (e.g. Baik, 1994; Moldovanu and Sela, 2001; Szymanski and Valletti, 2005; Minor, 2011) and empirically (e.g. Knoeber and Thurman, 1994; Brown, 2011).

The paper is organized as follows: Section 1 presents a two-stage model of an elimination tournament. We derive several propositions and outline the testable hypotheses. In Section 2, we describe our data and empirical strategy for testing these predictions. Section 3 
describes the results from past tournaments and discusses the spillover and shadow effects in the context of betting markets. We conclude in Section 4 and discuss the implications of our findings for contest designers.

\section{Theory}

We study a theoretical version of knockout tournaments in which matches within a given stage are staggered over time. Players in later matches learn the identity of their potential future opponent from outcomes of earlier matches. However, players in these earlier events can only form expectations about their future opponent. This formulation captures both sequential and simultaneous features of competition - just as players in simultaneous matches must form expectations about the outcomes of parallel games, so too must players in early matches of sequential tournaments form expectations about later matches.

This type of quasi-sequential play is often found in practice; for example, in firm-level tournaments, simultaneous promotions to division vice-president may be rare. Instead, the identity of the new appointee is known to other workers still competing for a parallel executive spot - the hopeful workers now know their future opponent for advancement beyond vicepresident. This structure is in contrast with other models of elimination tournaments where all matches in a given stage occur simultaneously rather than sequentially (for example, see Stracke (2011)). We use an additive noise model, as in Lazear and Rosen's (1981) foundational work on one-shot labor tournaments, to focus on the dynamics of a multi-stage elimination tournament. ${ }^{2}$

In the following section, we explore the role of past and future competition on tournament outcomes. We present a model that is simple enough to clearly inform our empirical tests, yet rich enough to capture common features of high-stakes, multi-stage tournaments. Namely, we model an elimination tournament with heterogeneously skilled players competing in sustained competition - one could imagine professionals of varying abilities competing over months or years for a prized position within the firm. ${ }^{3}$ In the main text, we consider these spillover and shadow effects separately for expositional ease; however, in the Appendix, we present an analysis of the effects operating simultaneously. Combining the effects does not change the general predictions of the model.

Our theory results describe the probability that the stronger player wins in different stages of the elimination event. These predictions speak directly to our broader research

\footnotetext{
${ }^{2}$ Additive noise models have been used in much of the labor tournaments literature since Lazear and Rosen (1981); for examples, see Konrad (2009).

${ }^{3}$ In a sports context, our model better reflects the dynamics of an endurance event (e.g. tennis) than competition requiring a short burst of effort (e.g. powerlifting).
} 
question of "selecting the best." That is, our comparative statics results provide predictions about when the strongest player is most likely to advance to future rounds of competition and, ultimately, win the tournament.

\section{$1.1 \quad$ Model Set-Up}

Consider a two-stage elimination tournament with four risk-neutral players, where the players who win in the first stage advance to the final stage. The overall tournament winner receives a prize of $V_{W}$, while the second-place competitor receives a prize $V_{L}$. Let $V_{W}>V_{L}>0$ and define the prize spread $\Delta V=V_{W}-V_{L}$. For simplicity, we assume no discounting across stages. Let player $i$ 's total cost be a quadratic function ${ }^{4}$ of his effort $x_{i}$ and his cost type $c_{i}{ }^{5}$ For simplicity, we denote player's common cost function as $\frac{1}{2} x^{2}$ and a player $i$ 's total cost as $c_{i} \frac{1}{2} x_{i}^{2}$. We assume that cost types, $c_{i}$, vary across all players and are commonly known amongst competitors. ${ }^{6}$ We will describe players with relatively low costs as being "stronger" than players with relatively high costs.

Recall that matches in the first-stage are sequential. Assume that players 3 and 4 compete first. Then, player 1 faces player 2 knowing the outcome of the previous match. However, players 3 and 4 will form an expectation of the strength of future competition, knowing only the identity of two potential opponents. Without loss of generality, we assume that player 3 won his match against player 4 .

\subsubsection{Final Stage of the Tournament}

Assume that player 1 won his first-stage match. To find the equilibrium of the multi-stage game, we begin by analyzing the strategies of player 1 and his opponent player 3 in the final

\footnotetext{
${ }^{4}$ Our results hold for more general convex cost functions, $\gamma\left(x_{i}\right)$, provided that both players' effort choices are sufficiently sensitive to a change in marginal benefit. In particular, we require that $\frac{\gamma^{\prime \prime}\left(x_{1}^{*}\right)}{\gamma^{\prime \prime}\left(x_{2}^{*}\right)}<\frac{c_{2}}{c_{1}}$. This condition on the slope of the marginal cost curve insures that the stronger player is sufficiently sensitive to a change in marginal benefit induced by a weaker future opponent; this further improves the stronger player's probability of winning in the first stage. For example, it can be shown that this inequality is satisfied with all cost functions of the form $c x^{p}$ where $p>1$. A sufficient but slack condition for the inequality is $\gamma^{\prime \prime \prime} \leq 0$. Note that cost functions of the form $c x^{p}$ with $p>2$ fail to satisfy $\gamma^{\prime \prime \prime} \leq 0$, but still meet the necessary condition of $\frac{\gamma^{\prime \prime}\left(x_{1}^{*}\right)}{\gamma^{\prime \prime}\left(x_{2}^{*}\right)}<\frac{c_{2}}{c_{1}}$. Ederer (2010) discusses models where the results instead depend critically on the sign of $\gamma^{\prime \prime \prime}$.

${ }^{5}$ One could define a mapping $E: \mathbb{R}_{+}^{N} \rightarrow \mathbb{R}_{+}^{1}$ that collapses levels of $N$ effort-generating activities to the real line. The overall cost of effort is then strictly increasing in the resultant scalar $x_{i}$.

${ }^{6}$ For ease of exposition, we model heterogeneity through players' cost types. However, several alternative models produce identical results: for example, we can also capture heterogeneity across valuations by defining a player's prize value as $\frac{V}{c_{i}}$ or by allowing the impact of an additional unit of effort on a player's probability of winning to vary across competitors. It can also be shown that capturing heterogeneity by varying cost function convexity leads to similar results.
} 
stage. Define player 1's expected payoff function as

$$
\pi_{1, f \text { inal }}=P_{1}\left(x_{1}, x_{3}\right) \Delta V-\frac{1}{2} c_{1} x_{1}^{2}+V_{L}
$$

where his probability of winning takes the following form:

$$
P_{1}\left(x_{1}, x_{3}\right)=\left\{\begin{array}{c}
1 \text { if } x_{1}+\varepsilon_{1}>x_{3}+\varepsilon_{3} \\
\frac{1}{2} \text { if } x_{1}+\varepsilon_{1}=x_{3}+\varepsilon_{3} \\
0 \text { otherwise }
\end{array}\right.
$$

where $x_{i}+\varepsilon_{i}$ is player $i$ 's level of output. Output is a function of both effort $x_{i}$ and a random noise term $\varepsilon_{i}$. In definition (2), the probability that player 1 wins is increasing in his own effort and decreasing in the effort of his opponent.

Define $\varepsilon=\varepsilon_{3}-\varepsilon_{1}$ and let $\varepsilon$ be distributed according to some distribution $G$ such that probability (2) can be written as

$$
P_{1}\left(x_{1}, x_{3}\right)=\operatorname{Pr}\left(x_{1}-x_{3}>\varepsilon\right)=G\left(x_{1}-x_{3}\right)
$$

Now, player 1's payoff function (1) can be written as

$$
\pi_{1, \text { final }}=G\left(x_{1}-x_{3}\right) \Delta V-\frac{1}{2} c_{1} x_{1}^{2}+V_{L}
$$

and his first order condition is

$$
\frac{\partial \pi_{1, \text { final }}}{\partial x_{1}}=G^{\prime}\left(x_{1}-x_{3}\right) \Delta V-c_{1} x_{1}=0
$$

Following Konrad (2009) and Ederer (2010), we assume that $G$ is distributed uniformly with the following support ${ }^{7}$

$$
G \sim U\left[-\frac{1}{2} a, \frac{1}{2} a\right]
$$

and, therefore,

$$
G^{\prime}=\frac{1}{a}
$$

The assumption that $G$ is uniformly distributed removes the strategic interdependence

${ }^{7}$ To ensure that probabilities are well-defined, we require that

$$
0<\frac{\frac{\Delta V}{a c_{1}}-\frac{\Delta V}{a c_{3}}+\frac{a}{2}}{a}<1
$$

This condition ensures that $G(\cdot) \in(0,1)$. 
of players' current period effort choices (Konrad, 2009). This allows us to isolate the consequences of past effort choices and potential future competition on current-stage effort. In a firm context, this would assume that a worker's optimal effort choice is independent of the identity of his current opponent; of course, in earlier stages, his optimal effort depends on his expectations about future opponents' identities. In the Appendix, we relax this assumption of same-stage independence and allow players' optimal effort choices to depend on both their current and future opponents. We show that the broad predictions of the model continue to hold with more general distributions that allow for same-stage interdependence, including the normal distribution.

Rewriting the first order condition (5) yields:

$$
\frac{\partial \pi_{1, \text { final }}}{\partial x_{1}}=\frac{\Delta V}{a}-c_{1} x_{1}=0
$$

which we can rearrange as the following expression:

$$
x_{i}^{*}=\frac{\Delta V}{a c_{i}} \text { for } i=1,3
$$

Assume for the remainder of the analysis that player 1 is the stronger player $\left(c_{1}<c_{3}\right)$. Then, expression (6) implies that player 1 exerts more effort in the final stage $\left(x_{1}^{*}>x_{3}^{*}\right)$. Therefore, the stronger player is more likely to win in the final stage, relatively to his weaker opponent - that is, the better player is more likely to be "selected" as the overall tournament winner.

In the final round, since both players are guaranteed at least the second prize $V_{L}$, increasing the first prize amounts to increasing the stakes of the contest. As expected, higher stakes leads to more effort from both players, though the stronger player increases his effort more than the weaker player. Also, increasing the noise around effort (i.e., increasing $a$, the width of the support of $G$ ) reduces effort, particularly for the stronger player.

\subsubsection{First Stage of the Tournament}

Define $z_{1}$ and $z_{2}$ as the efforts of players 1 and 2 in the first stage. Player 1 's expected payoff function in the first stage is

$$
\pi_{1, f i r s t}=P_{1}\left(z_{1}, z_{2}\right) \tilde{V}_{1}-\frac{1}{2} c_{1} z_{1}^{2}
$$


where $\tilde{V}_{1}$ is his continuation value (i.e., his payoff in the final stage):

$$
\tilde{V}_{1}\left(x_{1}, x_{3}\right) \equiv \pi_{1, \text { final }}=G\left(x_{1}-x_{3}\right) \Delta V-\frac{1}{2} c_{1} x_{1}^{2}+V_{L}
$$

Equation (7) yields the first order condition

$$
\frac{\partial \pi_{1, \text { first }}}{\partial z_{1}}=\frac{\tilde{V}_{1}}{a}-c_{1} z_{1}=0
$$

which we can rearrange, for either player, as the following expression:

$$
z_{i}^{*}=\frac{\tilde{V}_{i}}{a c_{i}} \text { for } i=1,2
$$

Fixing the player's continuation value, his effort $z_{i}^{*}$ is decreasing in $c_{i}$. Since the continuation value itself is also decreasing in $c_{i}$, first-stage effort $z_{i}^{*}$ is increasing in a player's ability (decreasing in $\left.c_{i}\right) .^{8}$

Recall that, at the start of their match, players 1 and 2 already know the outcome of the other first-stage match between players 3 and 4 . Of course, this means that players 3 and 4 did not know exactly the identity of their future opponent. Instead, we assume that they formed an expectation of their continuation value as follows:

$$
\mathrm{E}\left[\tilde{V}_{i}\right]=p_{1 \mid i} \tilde{V}_{i}\left(x_{i}^{*}, x_{1}^{*}\right)+\left(1-p_{1 \mid i}\right) \tilde{V}_{i}\left(x_{i}^{*}, x_{2}^{*}\right) \text { for } i=3,4
$$

where $p_{1 \mid i}$ is the equilibrium probability that player 1 wins knowing that he will face player $i$ in the final stage. ${ }^{9}$ Note that player $i$ cannot influence this probability $p_{1 \mid i}$ because it is a function of the realized outcome of the completed match between players 3 and 4 . This simplifies our analysis because player $i$ 's first-stage effort $z_{i}$ does not change this probability

${ }^{8}$ We can also express player $i$ 's first-stage effort as

$$
z_{i}^{*}=\frac{\left(\frac{\frac{\Delta V}{a c_{i}}-\frac{\Delta V}{a c_{3}}+\frac{1}{2} a}{a} \Delta V-\frac{1}{2} c_{i}\left(\frac{\Delta V}{a c_{i}}\right)^{2}+V_{L}\right)}{a c_{i}}
$$

and so

$$
\frac{\partial \tilde{V}_{i}}{\partial c_{i}}=-\frac{1}{2} \frac{\Delta V^{2}}{a^{2} c_{i}^{2}}<0
$$

${ }^{9}$ When player 1 is stronger than player $2, \tilde{V}_{i}\left(x_{i}^{*}, x_{1}^{*}\right)<\mathrm{E}\left[\tilde{V}_{i}\right]<\tilde{V}_{i}\left(x_{i}^{*}, x_{2}^{*}\right)$ for $i=3,4$. 
$p_{1 \mid i}$. Thus, for players 3 and 4 , we can express their effort as

$$
z_{i}^{*}=\frac{\mathrm{E}\left[\tilde{V}_{i}\right]}{a c_{i}} \text { for } i=3,4
$$

and the analysis described above for players 1 and 2 applies similarly.

\subsection{Shadow of Future Competition}

We can use the model to understand the impact of known or expected future competition on the likelihood that stronger players advance to future stages of the tournament - of course, this then influences the likelihood that a high-skill player is selected as the overall winner.

Consider an increase in the skill of the future opponent. This change has the effect of decreasing the continuation value for both players 1 and 2 in the first stage. In the following analysis, we show that if player 1 has a lower cost of effort than player 2 , then he will decrease his first-stage effort more than player 2 .

We can express player $i$ 's $(i \in\{1,2\})$ first-stage effort as

$$
z_{i}^{*}=\frac{\tilde{V}_{i}}{a c_{i}}=\frac{\left(\frac{\frac{\Delta V}{a c_{i}}-\frac{\Delta V}{a c_{3}}+\frac{1}{2} a}{a} \Delta V-\frac{1}{2} c_{i}\left(\frac{\Delta V}{a c_{i}}\right)^{2}+V_{L}\right)}{a c_{i}}
$$

To identify the effect of a change in the effort cost of the future opponent, we take the derivative

$$
\frac{\partial z_{i}^{*}}{\partial c_{3}}=\frac{\Delta V^{2}}{a^{3} c_{i} c_{3}^{2}}>0
$$

Thus, an increase in the skill of the future opponent (i.e. a decrease in $c_{3}$ ) decreases a player's effort in the first stage. This is consistent with Ryvkin (2009) who finds that, in tournaments with weakly heterogeneous players, effort depends negatively on future opponents' skill.

Since we are additionally concerned with tournament outcomes, we next ask: Which first-stage player is more sensitive to the change in the future competition? Let $c_{1}<c_{2}$. Then,

$$
\frac{\partial z_{1}^{*}}{\partial c_{3}}=\frac{\Delta V^{2}}{a^{3} c_{1} c_{3}^{2}}>\frac{\Delta V^{2}}{a^{3} c_{2} c_{3}^{2}}=\frac{\partial z_{2}^{*}}{\partial c_{3}}
$$

This means that, for a given increase in the talent of the future competitor, player 1 decreases his effort even more than player 2. Thus, player 1 is less likely to win in the current period. This gives us the first proposition:

Proposition 1 As the skill of the future competitor in the final stage increases (declines), 
the stronger player becomes less (even more) likely to win in the first stage and thus less (even more) likely to be selected as the overall tournament winner.

\subsection{Effort Spillover}

We can also examine effort spillover between stages of the tournament. Spillover can take either a positive or negative form. Positive spillover might reflect learning-by-doing, skill building or momentum within a firm. For example, an innovation team whose proposal advances to a second stage of funding might benefit from its first-stage experiences, both technical and relational. With positive spillover, second-stage effort is less costly than first stage effort. In contrast, negative spillover might reflect fatigue or reduced resources in later stages. For example, architects competing in design competitions might exhaust their creative resources in early stages and have only limited energy for second-stage proposals. In this case, second-stage effort is more costly than first-stage effort. ${ }^{10}$

Consider a scenario where effort expended by a player in the first stage influences his cost of effort in the final stage. ${ }^{11}$ We can rewrite player 1's final-stage payoff as

$$
\pi_{1, f i n a l}=G\left(x_{1}-x_{3}\right) \Delta V-\frac{1}{2} k c_{1} x_{1}^{2}+V_{L}
$$

where $k$ reflects the change in total cost induced by first stage effort.

To study a negative spillover effect, we let a player's marginal cost of effort in the final stage increase $(k>1)$ and final stage effort is strictly decreasing in the degree of negative spillover. With positive spillover, a player's marginal cost of effort in the final stage decreases $(k<1)$ and final stage effort is increasing in positive spillover.

Now, equilibrium effort is

$$
x_{1}^{*}=\frac{\Delta V}{k a c_{1}}
$$

Straightforward calculations show that negative (positive) spillover reduces (increases) a player's final-stage payoff. Consequently, first-stage effort decreases (increases) with negative (positive) spillover.

Thus, negative spillover implies a lower probability of success in the final stage, holding the opponent's effort and skill constant. Of course, the opposite is true for positive spillover.

\footnotetext{
${ }^{10}$ Different notions of spillover have been explored in the literature in settings where players with exogenous, fixed resources make effort allocation decisions over multiple periods of play. For recent examples, see Sela and Erez (2011) and Harbaugh and Klumpp (2005).

${ }^{11}$ If previous effort appears only as a fixed cost in the final stage, we would expect no change in final-stage effort.
} 
Since

$$
\frac{\partial x_{1}^{*}}{\partial k}=-\frac{\Delta V}{k^{2} a c_{1}}<-\frac{\Delta V}{k^{2} a c_{3}}=\frac{\partial x_{3}^{*}}{\partial k}
$$

when both players in a match suffer similar negative spillover, the stronger player is more adversely affected. As a result, he is relatively less likely to win. In the limit, $G\left(x_{1}^{*}-x_{3}^{*}\right) \rightarrow$ 0.5 as the degree of negative spillover $k \rightarrow \infty$.

We summarize this finding in the second proposition:

Proposition 2 A common proportional increase in effective cost type decreases the probability that the stronger player is selected as the winner.

This proposition suggests that, with negative spillover, weaker players might support costlier competitive conditions - for example, a weaker player might advocate for more stringent common standards or more difficult tasks. Overall, however, the direction and impact of spillover depends on the context and, thus, is an empirical question.

Our result that negative spillover levels the playing field in both stages is in contrast to Harbaugh and Klumpp's (2005) finding that intertemporal tradeoffs level the playing field for the first stage, but do the opposite in the final stage. Their result is sensitive to the assumptions that effort is costless and that players' total efforts are equally constrained.

Spillover need not be modeled as a common proportional increase in marginal cost; in the Appendix, we allow the degree of spillover to be a function of first stage effort and achieve similar results.

\subsection{Model Predictions}

The theory model outlined above provides the following main predictions: ${ }^{12}$

1. Shadow of Future Competitors: The stronger the expected competitor in the next stage, the lower the probability that the stronger player is selected as the winner in the current stage. Empirically, for a given pair of competitors, we expect that the stronger player is less likely to win when the winner of the current match will face a stronger future opponent.

\footnotetext{
${ }^{12}$ Other predictions follow immediately from our analysis: (a) the noisier the effort-to-output relationship, the lower the probability that the stronger player wins in either stage; (b) a steeper prize structure improves the stronger player's probability of success in all stages; and (c) fixing the competitors' abilities and given a sufficiently large (small) second-place prize, the probability of winning is greater (smaller) for the weaker player in the final stage, relative to the first stage. Proofs for these additional results are available from the authors upon request.
} 
2. Effort Spillover between Stages: Increased negative (positive) spillover decreases (increases) the probability that the stronger player is selected as the winner in the final stage. Empirically, for a given pair of competitors experiencing negative spillover, we expect that even similar levels of past exertion will make it less likely that the stronger player wins.

Note that the model's implications are framed in terms of outcomes, allowing us to readily test these predictions by observing tournament winners. In the following sections, we describe our data and empirical analysis.

\section{Data}

Professional tennis offers an ideal environment in which to test the empirical implications of the theory. ${ }^{13}$ Tennis events are single-elimination tournaments - only winning players advance to successive stages until two players meet in the final stage to determine the overall winner. Prizes increase across stages with the largest prize going to the overall winner. The distribution of prizes is known in advance for all tournaments. The financial stakes are substantial and vary across events - for example, the total purse for the 2009 US Open singles competition was $\$ 16$ million with a $\$ 1.7$ million prize for first place, while the total purse for the 2009 SAP Open was $\$ 531,000$ and the winner received $\$ 90,925$.

Our empirical analysis exploits the random nature of the initial tournament draw. By ATP rules, the top 20 to $25 \%$ of players in an event (the "seeds") are distributed across the draw: the top two seeds are placed on opposite ends of the draw; the next two seeds are randomly assigned to interior slots on the draw; the next four seeds are randomly assigned to other slots; etc. After the seeded players have been assigned, the remaining players are then randomly placed in matches prior to the start of the event. ${ }^{14}$ This variation provides the identification for our empirical approach - we can observe the same skilled player compete against a variety of randomly-assigned opponents. For example, in our data, we can observe the fourth best player in the world play against competitors ranked $50^{\text {th }}, 100^{\text {th }}$, and $250^{\text {th }}$ in the first round of the same tournament over different years.

The structure of tennis tournaments is particularly conducive to studying the shadow of future competition - both players (and the econometrician) know the competitors in the

\footnotetext{
${ }^{13}$ While tennis tournament organizers may have various objectives beyond selection, it is the structure of these tournaments that lends itself to our empirical tests. One would expect tournament competitors to respond to the structure and incentives, not the reason for that contest design

${ }^{14}$ Note that the seeding is done according to rank within a tournament; the top seed in one event may have a different ATP ranking than the top seed in another tournament.
} 
parallel match. In some cases, players know exactly who they would face in the next round; in other cases, they can make reasonable predictions about upcoming opponents. Measures of players' abilities are also observable to competitors and researchers - past performance data, as well as world rankings statistics, are widely available. Figure 1 presents the draw from the 2007 Swiss Indoors tournament in Basel. In the first round, Del Potro and Russell knew that their next opponent would be either Federer or Berrer. Of course, given the ability difference between these possible future opponents, Del Potro and Russell were likely predicting that their second-round opponent would be Federer.

Data from professional tennis has been used in other research: Walker and Wooders (2001) used video footage and data from the finals of 10 Grand Slam events to identify mixed strategies. Malueg and Yates (2010) study best-of-three contests using four years of data from professional tennis matches with evenly-skilled opponents. They find that the winner of the first set of a match tends to exert more effort in the second set than does the loser and, in the event of a third set, players exert equal effort. Forrest and McHale (2007) use professional tennis bookmaking data and find a modest long-shot bias. Gonzalez-Diaz et al. (2012) use data from US Open tournaments to assess individual players' abilities to adjust their performance depending on the importance of the competitive situation. They find that heterogeneity in this ability drives differences in players' long-term success. Using detailed data from the men's and women's professional tennis circuits, Gilsdorf and Sukhatme (2008a and 2008b) find that larger marginal prizes increase the probability that the stronger player wins.

\subsection{Professional Tennis Match Data}

To test the predictions outlined in the theory, we examine the behavior of professional tennis players in 615 international tournaments on the ATP World Tour between January 2001 and June 2010. The data include game-level scores and player attributes for men's singles matches (available at http://www.tennis-data.co.uk). The four "Grand Slam" events - the Australian, French, and US Opens, and Wimbledon - are included in the data. All of the tournaments are multi-round, single-elimination events played over several days.

Tournament draws may include $28,32,48,56,96$ or 128 players. Of the 615 events in the data, 432 tournaments consist of five rounds of play-rounds 1 and 2, quarterfinals, semifinals, and the final. Six rounds are played in 129 events. Fifty-four tournaments, including the Grand Slam events, consist of seven rounds of play-rounds 1 to 4, quarterfinals, semifinals, and the final. Most ATP events are best-of-three sets, while the Grand Slam events 
are best-of-five sets. ${ }^{15}$ Figure 1 shows a typical draw for a five-round, 32-player tournament. Depending on the number of competitors, first-round byes may be awarded to the top-ranked players. $^{16}$

World rankings (officially called the South African Airways ATP Rankings) are based on points that players accumulate over the previous 12 months. ATP points directly reflect the pyramid structure of tournaments; more points are awarded to players who advance in top tournaments. For example, a Grand Slam winners earns the maximum points awarded for a single event. ${ }^{17}$ ATP rankings are simply a rank-order of all players by their accumulated points. In our analysis, we use the ATP rankings to account for players' skill levels.

Table 1 presents summary statistics from over 28,000 men's professional tennis matches. On average, matches are decided after approximately 23 games in five- and six-round tournaments and 32 games in seven-round tournaments, many of which are decided by best-of-five sets. Match winners are significantly more skilled than losers $(p<0.01)$. Tournaments' seeding formats generally pair the weakest players against the strongest players in the first round. Consequently, the disparity in rankings decreases as players advance. To consider the competitive balance of matches across rounds, we also report the rank ratio (worse rank divided by better rank). Mean rankings ratios remain relatively stable across rounds.

\section{Results}

In this section, we present empirical tests of the theoretical predictions. We first examine performance data from professional tennis matches, presenting empirical results supporting both spillover and shadow effects. Next, we ask whether shadow and spillover effects have been priced into betting markets. Although this additional analysis is not a direct test of the theory, it does provide further support for the importance of understanding these phenomena.

\subsection{Spillover and Shadow Effects in Match Outcomes}

Proposition 1 states that tougher future competition will decrease the stronger competitor's probability of success in the current stage. This prediction follows from the observation that, while stronger future competition will cause both players to decrease their effort in the

\footnotetext{
${ }^{15}$ To win a set, a player must win at least six games and at least two games more than his opponent. A game is won by the player who wins at least four points and at least two more than his opponent. Set tie-break rules vary by tournament.

${ }^{16}$ Byes automatically advance a player to the next round.

${ }^{17}$ For details of the world ranking system, see the 2011 ATP World Tour Rulebook, available online at www.atpworldtour.com.
} 
current period, the current effort of the better-ranked player decreases even more than the current effort of his worse-ranked opponent. Proposition 2 considers the role of spillover in effort choice. The direction of the spillover effect is often an empirical question; however, one might expect negative spillover in events that require intense effort exertion over a short period of time. In professional tennis, players may face a higher cost of effort if exertion in previous matches induced lasting fatigue.

The following specification allows us to study the effects of shadow and spillover simultaneously:

$$
\begin{aligned}
\text { strongwins }_{m t}= & \beta_{0}+\beta_{1} \text { Future }_{m t}+\beta_{2} \text { SPastGames }_{i t} \\
& +\beta_{3} \text { WPastGames }_{i t}+\beta_{4} \text { Current }_{m t}+\gamma X_{t}+\varepsilon_{m t}
\end{aligned}
$$

where strongwins $s_{m t}$ is a binary indicator of whether the better-ranked player in match $m$ won in a stated round of tournament $t$, Future $_{m t}$ represents the expected ability of the opponent in the next round, Current ${ }_{m t}$ represents the degree of heterogeneity of players' skills in the current match, SPastGames $i t$ is the number of games played in all previous rounds of the tournament by the better-ranked player, WPastGames ${ }_{i t}$ is the number of games played in all previous rounds of the tournament by the worse-ranked player, $X_{t}$ is a matrix of tournament-level controls, and $\varepsilon_{m t}$ is the error term. ${ }^{18}$ We estimate all equations using a linear probability model (OLS) with a robust variance estimator. Results are quantitatively very similar for a probit specification; coefficient estimates for the probit are presented in Appendix Table A1.

Future $_{m t}$ is the rank associated with the stronger player in the parallel match. ${ }^{19}$ For example, for the 2007 Swiss Indoors tournament (see Figure 1), the expected future opponent for the match between Del Potro and Russell would be Federer. For the Del Potro-Russell match, Future $_{m t}=1$. Results are qualitatively similar if we instead use an average of future opponents' rankings or a transformation suggested by Klaassen and Magnus (2003). ${ }^{20}$ Current $_{m t}$ is the ratio of the rank of the worse player and the better player. We estimate, but do not report, results for regression (9) using ATP points as a measure of player skill. Estimates are qualitatively similar to results using ATP rankings.

Tournament-specific fixed effects capture average event-level characteristics and control for differences between tournaments (e.g. media attention). Total purse size for any given

\footnotetext{
${ }^{18}$ Recall that current competitors faced different opponents in previous rounds and, therefore, may have played a different number of previous games.

${ }^{19}$ We later restrict our sample to matches in which players know their future opponent with certainty.

${ }^{20}$ Klaassen and Magnus (2003) calculate a player's ability as $R=K+1-\log _{2}(\operatorname{ranking})$, where $K$ is the total number of rounds in the tournament and ranking is the player's tournament seed.
} 
event has not varied substantially across time. For example, the purse for the US Open has grown by an average of 3\% each year from 1997 to 2011. Over the same period, the inflation rate was roughly the same. Therefore, real purse size was relatively stable and the purse effect is captured by tournament dummies. Additionally, because some tournaments have changed venues over time, we include additional controls for surface and court type.

In the following analysis, we examine separately tournaments with five, six or seven rounds of play. This accounts for both heterogeneity between tournament types and structure for example, the quarterfinal competitor casts a shadow on the second round in a five-round tournament and the fourth round of a seven-round event; and accumulated spillover in a quarterfinal match in a five-round event may have a considerably different effect than in a seven-round event.

We report results for regression (9) by tournament round. The round-by-round analysis overcomes the confounding influence of changes in marginal prizes across rounds within a tournament, while still controlling for the differences in prizes for a given round across events. Moreover, it allows us to cleanly account for players' past exertion (and the hypothesized spillover effect) without concerns about the autocorrelation of the same player's performance and effort over several rounds of a single tournament.

\section{Results: Actual Match Outcomes}

Table 2 presents results for the main specification for five-, six- and seven-round events. ${ }^{21}$ For five-round events, the coefficient on the shadow effect $\left(\right.$ Future $\left._{m t}\right)$ is positive and statistically significant in the first and second rounds $(p<0.01)$. The stronger (i.e. better ranked) the future opponent, the lower the probability that the stronger player is selected as the winner in the current round. For a one standard-deviation decrease in future opponent's rank (increase in ability), we estimate that the probability that the stronger player wins in the current round decreases by approximately 2 percentage points. Given that the average probability that the stronger player wins is approximately $64 \%$, on average, the shadow effect represents a $3 \%$ decline in the probability of winning. The estimated effects for the quarterfinals and semifinals are also positive and similar in magnitude, but are not statistically significant - this may reflect both small sample sizes and limited variation in opponents' skills at advanced stages of these tournaments.

For six-round events, the estimates of the shadow effect are positive, but is only statistically significant in the third-round $(p<0.05)$. However, for seven-round events, the shadow effect is statistically significant for the first four rounds $(p<0.05)$. In these high-stake tour-

\footnotetext{
${ }^{21}$ Note that the first and last columns of Table 2 omit estimates for spillover and shadows, respectively because there is no spillover for players in the first round of a tournament and players face no shadow in the final round.
} 
naments, one standard-deviation increase in future opponent's ability is associated with a 3.5 percentage point decrease in the probability that the stronger player wins in the current round; this implies a $5 \%$ decline in the probability that the strong player wins.

In general, coefficient estimates for the two spillover variables take on predicted signs: more previous games for the stronger player decreases the probability he wins in the current match, while in general more previous games for the weaker player increases the chance that the stronger player wins. In longer events, spillover effects are smaller in magnitude and are not statistically significant in the final rounds, perhaps because players typically get more rest days for these later stage matches. The history of the stronger player appears to drive his current success more than the history of his opponent - from expression (10) of our model, we expect the stronger player to be more adversely affected than the weaker player for a given increase in spillover. Indeed, in the data, the effect of previous games played by the stronger player is often larger than the effect of the weaker player's previous games.

In five-round tournaments, the estimated effect of spillover for stronger players ranges from -0.15 to $-0.44 \%(p<0.1)$. On average, a one standard-deviation increase in the number of previous games is associated with a decline of approximately 1 to 3 percentage point decline in the probability of winning in the current match for the stronger player; this represents a 1 to $4.5 \%$ decline in the probability of winning. In six-round events, the estimates for the spillover effects are statistically significant in four rounds for the stronger player and in two rounds for the weaker player. In these events, a one standard-deviation increase in the number of previous games is associated with a roughly 2 percentage point decline in the probability of winning in the current match for the stronger player. For seven-round events, the spillover effects for the stronger player are negative and statistically significant in three of the six cases.

As expected, the coefficients on skill disparity in the current match are all positive and, with few exceptions, statistically significant. This suggests that increased heterogeneity between the players increases the probability that the stronger player wins.

\section{The Role of Top Seeded Players}

As described in Section 2, most players are randomly assigned to a position in the tournament draw. The exceptions are the top two seeded players who are assigned to opposite ends of the draw - this prevents the top two seeds from meeting in the early rounds. Although we use players' world rank (and not their tournament-specific seed number) in the empirical analysis, a robustness check ensures that the results are not sensitive to the fact that top players' positions are not randomly assigned. We replicated the analysis in Table 2 while excluding matches in which the top two seeded players compete. This restriction

excludes roughly $10 \%$ of the observations - from 200 to 1400 observations per round across 
tournament types. Overall, the regression results are qualitatively similar to those in Table 2 ; however, the pattern of statistical significance is less pronounced. ${ }^{22}$

\section{The Order of Match Resolution}

In the main analysis, we assume that the shadow was the rank of the stronger of the players from the parallel match. Due to data limitations, the exact sequence of matches is not broadly available; however, we instead construct a dataset of matches for which the sequence of resolution can be established by identifying parallel matches that were played on different days. This small subset of the data includes only $10 \%$ of all matches. Unfortunately, we cannot identify cases in which parallel matches were played sequentially on the same day - a common feature of most tournaments' schedules. As a result, our subsample may not be representative of all cases in which competitors know their future opponent. In Table 3, we report results from regression (9) where the shadow is the rank of the realized winner of the parallel match. Although statistical significance is weak-likely due to the very limited sample size - we observe the general pattern of results that we also identified in Table 2; shadow effects tend to be positive and the increased heterogeneity always improves the probability that the stronger player wins.

\section{Long Shadow}

Motivated by the simple two-stage model in Section 1, the main empirical specification in Table 2 considers the impact of the expected opponent in the next round of the tournament. It is possible, however, that players respond to a "longer" shadow - in principle, players could look at the full tournament roster and adjust their effort in response to the presence of a single stronger player. For example, these effort adjustments might take the form of changes in training activities for an upcoming tournament, which can be physically and mentally costly for professional players. To consider this possibility empirically, we expand the main specification to include the ATP rank of the most able opponent in the tournament and report the results in Table $4 .^{23}$

In all but one case, the coefficient on the new variable, the rank of the most able opponent in the tournament, is either positive and statistically significant or indistinguishable from 0. That is, the presence of a strong player in the tournament - not necessarily even in the next immediate rounds - may lower the chance that the stronger player wins in the current match. The inclusion of the rank of the most able opponent does not change the interpretation of the main empirical results - a tougher next-round opponent still reduces the probability that the stronger player wins in the current round. The magnitudes of the estimates and the pattern

\footnotetext{
${ }^{22}$ Results are available from the authors upon request.

${ }^{23}$ For most players, this is the best-ranked player in the tournament; for matches involving the best-ranked player, the most able opponent is the second best-ranked competitor in the event.
} 
of statistical significance in Table 4 are very similar to those in Table 2; the only exception is for the stronger players' spillover in the semifinals of seven round events.

\subsection{Shadow and Spillover Effects in Betting Markets}

In this section, we explore whether active markets account for the shadow and spillover dynamics of multi-stage competition. By examining data from professional betting markets, we find compelling evidence that subtle spillover and shadow effects have been incorporated into prices.

The efficiency of prediction and betting markets has been studied extensively in the literature; for examples, see the survey by Vaughan Williams (1999). Prediction markets are founded on the argument that by aggregating information, competitive markets should result in prices that reflect all available information (Fama 1970). Therefore, driven by aggregated information and expectations, prediction market prices may offer good forecasts of actual outcomes (Spann and Skeira 2003).

Similarly, betting odds reflect bookmakers' predictions of future outcomes. Betting odds may change as new public or private information becomes available to the bookmaker and with changes in the volume of bets that may be driven by individual bettors' private information. As with formal prediction markets, we might expect betting odds to provide good forecasts. Spann and Skeira (2008) compare forecasts from prediction markets and betting odds using data for German premier soccer league matches. They find that prediction markets and betting odds provide equally accurate forecasts.

To examine whether betting markets incorporate information about the effects of shadow and spillover, we estimate a regression similar to equation (9). Now, instead of a binary indicator of the actual outcome, the dependent variable is the probability that the stronger player wins the match as implied by betting markets.

Our data include closing odds from professional bookmakers for pre-match betting. ${ }^{24}$ Woodland and Woodland (1999) note that bookmakers adjust odds based on the volume of bets, making the odds available as the betting market closes particularly rich in information. In our analysis, we use the median of the available odds data since the data from no single firm covered all matches. ${ }^{25}$ Overall, there was little variation between odds posted by different bookmakers for the same match, perhaps because participants in tennis betting markets tend

\footnotetext{
${ }^{24}$ Data from 11 betting firms (Bet365, Bet\&Win, Centrebet, Expekt, Ladbrokes, Gamebookers, Interwetten, Pinnacles, Sportingbet, Stan James, and Unibet) are included in our main dataset obtained from www.tennis-data.co.uk. Several betting firms also offer in-play betting, but we focus our analysis on prematch bets only.

${ }^{25}$ We calculate the probability odds from the decimal odds in the original data. Probability odds are $1 /$ (decimal odds - 1).
} 
to be specialists and there is little casual betting (Forrest and McHale 2007).

Table 4 reports the implied probabilities that the stronger player wins across rounds in five-, six- and seven-round tournaments. On average, the stronger player is predicted to win; the betting market favors the stronger player approximately $70 \%$ of the time, with slightly more favorable predictions in high-stakes, seven-round tournaments. The accuracy of odds market predictions suggests that information beyond simple rankings are being priced into the market. Between 2001 and 2010, predictions from the market are correct for $69 \%$ of the 25,633 matches for which betting data are available. Given that the stronger player actually wins in $65 \%$ of the matches, one might not be surprised by this accuracy if the market always predicted that the stronger player wins. However, in $18 \%$ of the matches, the betting odds imply that the weaker player is expected to win. Interestingly, these market predictions are accurate nearly $63 \%$ of the time. That is, these betting markets do almost as well predicting an upset as they do predicting a win by the stronger player. This is particularly notable since a naive assessment of the ATP rankings in these matches might suggest that the odds are still solidly against the weaker player; on average, the weaker player's rank is 2.1 times higher (worse) than his opponent.

\section{Results: Betting Market Predictions}

Table 5 reports results for regressions where the dependent variable is the probability that the stronger player wins as implied by the betting market. Overall, coefficient estimates suggest that the betting predictions incorporate information about players' past and expected future competition.

Coefficient estimates for the effect of a stronger future opponent are positive and statistically significant for 10 of 15 cases in Table 5 . In particular, the shadow effects are positive and statistically significant in early rounds of five-, six- and seven-round tournaments $(p<0.01)$. The shadow effects are also positive in the final stages of six-round tournaments. It is not surprising that we do not identify the effect of the shadow in late stages of five- and seven-round events, given the compressed distribution of skill at the end of the tournament.

Since betting markets close at the start of the match, players' past exertion information is readily available to bookmakers. Indeed, coefficient estimates for the stronger and weaker players' previous number of games are statistically significant and take on the expected signs in 26 of 30 cases $(p<0.01)$. More previous games played by the stronger player is associated with a decrease in the expectation of his success, while more previous games played by the weaker player is associated with an increase in the expectation that the stronger player wins. The magnitudes of these effects also align with predictions from our model — stronger players are more sensitive to an additional unit of spillover, compared to the weaker players.

Greater heterogeneity in players' abilities may increase the market's expectation that the 
stronger player wins - the coefficient on rank ratio is positive and statistically significant in all rounds $(p<0.01)$. Overall, we find strong evidence that prices in tennis betting markets reflect both the shadow and spillover effects predicted by our model.

\section{Unobserved Player Heterogeneity Across Rounds}

One advantage of the betting market data is that we can identify things that might otherwise be outside of the econometrician's observation. In particular, we can identify when there is a predicted upset - this prediction is based on observations of the bookmaker and not simply the ranks of the players. For example, if a player has a minor injury or seems to be in the midst of a short winning streak, his world rank would not reflect this transient state. However, bookmakers could integrate this information into their predictions about match outcomes.

We can identify predicted upsets by comparing the implied probability of the betting odds to the rank-based outcome prediction (i.e. the prediction that the stronger player is more likely to win). If the betting odds predict that the weaker ranked player has a better than $50 \%$ chance of winning, then there is some unobserved (to us) positive shock for him (and/or negative shock for the stronger player). Deviations from the ranked-based predictions that persist over multiple rounds suggest a state-dependent component of play. We take a conservative approach to identify this state-dependence.

There are 2085 predicted upsets in the data, representing roughly $7 \%$ of all matches. In 67 cases, a single player was predicted to cause multiple upsets in the same event. Fiftyseven of these instances involved two upsets in the same tournament; ten cases involved three predicted upsets. This means that more than $96 \%$ of predicted upsets did not persist beyond a single round. Overall, we find little evidence that match outcomes are driven by unobserved state dependence.

\section{Conclusion}

In this paper, we present a two-stage, match-pair tournament model that provides two sharp results: (a) a shadow effect of future competition - the tougher the expected competitor in the final stage, the lower the probability that the stronger player is selected as the winner in the first match; (b) an effort spillover effect - negative spillover has a relatively stronger adverse effect on the higher-skilled player.

We test our two main theoretical hypotheses using data from professional tennis matches. We find evidence of a substantial shadow effect, where a stronger future competitor decreases the probability that the stronger player wins the current match. We also identify a negative spillover effect in tennis tournaments - more effort exertion in the previous rounds is asso- 
ciated with significantly less success in the current round, particularly for stronger players. In a second analysis, we use probability odds data from bookmakers to show that betting markets recognize and price in the spillover and shadow effects.

Our findings have implications in terms of the structure of elimination tournaments. Tournaments are often designed to identify high-ability candidates in environments where the contest organizer cannot readily observe innate talent. Our results suggest ways by which a contest designer can improve the likelihood that the strongest candidate succeeds.

Shrouding the skill of a strong future opponent increases players' continuation values, relative to the case where the player faces a stronger rival with certainty. This will elicit more effort, particularly from the stronger player, and improve the probability that the stronger player will win in the current match. Of course, the opposite is true if the contest designer shrouds the identity of a weaker future opponent. Overall, a shrouding policy could elicit more effort (and thus improve the likelihood of selecting a strong winner) in a setting where the future opponent is more likely to be strong, rather than weak. In practice, this shrouding could be implemented by delaying the announcement of winners from parallel matches.

Limiting negative spillover by allowing competitors opportunities to refresh their resources between stages may also increase the probability that the stronger type wins. In addition, firms may want to encourage positive spillover through learning. For example, in an innovation contest, firms should be given adequate time between stages to raise additional funds and pursue more advanced technology improvements. Similarly, a firm may wish to institute a "work-life balance" program that promotes employee wellness, discourages careerrelated burnout, and improves the probability that the firm's labor tournament promotes the strongest workers. In contrast, if a contest designer is concerned with the unevenness of competition, it can design a more balanced contest with more negative spillover. 


\section{References}

[1] Baik, K. H. 1994. Effort Levels in Contests with Two Asymmetric Players. Southern Economic Journal, 61(2): 3-14.

[2] Brown, Jennifer. 2011. Quitters Never Win: The (Adverse) Incentive Effects of Competing with Superstars. Journal of Political Economy: 119(5): 982-1013.

[3] Ederer, Florian. 2010. Feedback and Motivation in Dynamic Tournaments. Journal of Economics and Management Strategy, 19(3): 733-769.

[4] Fama, E. F. 1970. Efficient capital markets: a review of theory and empirical work. Journal of Finance, 25: 383-417.

[5] Forrest, David, and Ian McHale. 2007. Anyone for Tennis (Betting)? European Journal of Finance. 13(8): 751-768.

[6] Gilsdorf, Keith F., and Vasant Sukhatme. 2008a. Testing Rosen's Sequential Elimination Tournament Model : Incentives and Player Performance in Professional, Journal of Sports Economics, 9(3): 287-303.

[7] Gilsdorf, Keith F., and Vasant Sukhatme. 2008b. Tournament incentives and match outcomes in women's professional tennis. Applied Economics, 40(18): 2405-2412.

[8] Gonzalez-Diaz, Julio, Olivier Gossner, and Brian W. Rogers. 2012. Performing Best When It Matters Most: Evidence From Professional Tennis. Journal of Economic Behavior \& Organization. 84(3) December: 767-781.

[9] Groh, C., B. Moldovanu, A. Sela, and U. Sunde. 2008. Optimal seedings in elimination tournaments. Economic Theory. DOI: 10.1007/s00199-008-0356-6

[10] Harbaugh, Rick, and Tilman Klumpp. 2005. Early Round Upsets and Championship Blowouts. Economic Inquiry, 43(2): 316-329.

[11] Hvide, Hans K., and Eirik G. Kristiansen. 2003. Risk Taking in Selection Contests. Games and Economic Behavior, 42:172-179.

[12] Klaassen, Franc J. G. M. and Jan R. Magnus. 2003. Forecasting the winner of a tennis match. European Journal of Operational Research, 148(2) (July): 257-267.

[13] Knoeber, C. R. and W. N. Thurman. 1994. Testing the Theory of Tournaments: An Empirical Analysis of Broiler Production. Journal of Labor Economics, 12(2): 155-179. 
[14] Konrad, Kai A. 2009. Strategy and Dynamics in Contests. Oxford University Press.

[15] Lazear, Edward P. 1986. Salaries and Piece Rates. Journal of Business, 59(3): 405-431.

[16] Lazear, Edward P. and Sherwin Rosen. 1981. Rank-Order Tournaments as Optimum Labor Contracts. Journal of Political Economy, 89(5) (Oct.): 841-864.

[17] Malueg, David A., and Andrew J Yates. 2010. Testing Contest Theory: Evidence from Best-of-Three Tennis Matches. Review of Economics and Statistics, 92(3) (Aug.): 689692.

[18] Minor, Dylan B. 2011. Increasing Effort Through Softening Incentives. Working Paper.

[19] Rosen, Sherwin. 1986. Prizes and Incentives in Elimination Tournaments. The American Economic Review. 76(4) (Sept): 701-715.

[20] Ryvkin, Dmitry. 2009. Tournaments of Weakly Heterogeneous Players. Journal of Public Economic Theory 11(5): 819-855.

[21] Ryvkin, Dmitry. 2010. The Selection Efficiency of Tournaments. European Journal of Operational Research, 206: 667-675.

[22] Ryvkin, Dmitry, and Andreas Ortmann. 2008. The Predictive Power of Three Prominent Tournament Formats. Management Science, 54(3) March: 492-504.

[23] Schmitt, Pamela, Robert Shupp, Kurtis Swope, and John Cadigan. 2004. Multi-period rent-seeking contests with carryover: Theory and experimental evidence. Economics of Governance, 5: 187-211.

[24] Searls, Donald T. 1963. On the Probability of Winning with Different Tournament Procedures. Journal of the American Statistical Association, 58(304) (Dec.): 1064-1081.

[25] Sela, Aner, and Eyal Erez. 2011. Dynamic Contests with Resource Constraints. Working Paper.

[26] Spann, Martin, and Bernd Skiera. 2003. Internet-based virtual stock markets for business forecasting. Management Science, 49: 1310-1326.

[27] Spann, Martin, and Bernd Skiera. 2008. Sports Forecasting: A Comparison of the Forecast Accuracy of Prediction Markets, Betting Odds and Tipsters. Journal of Forecasting, 28: $55-72$. 
[28] Stracke, Rudi. 2011. Multi-Stage Pairwise Elimination Contests with Heterogeneous Agents. Working Paper.

[29] Sunde, Uwe. 2009. Heterogeneity and Performance in Tournaments: A Test for Incentive Effects Using Professional Tennis Data. Applied Economics, 41(25): 3199-3208.

[30] Tullock, Gordon. 1980. Efficient rent seeking. In: J. M. Buchanan, R. D. Tollison, and G. Tullock. (eds.) Toward a theory of the rent-seeking society. College Station: Texas A\&M University Press.

[31] Vaughan Williams, Leighton. 1999. Information Efficiency in Betting Markets: a Survey. Bulletin of Economic Research, 51(1) (Jan.): 1-39.

[32] Walker, Mark, and John Wooders. 2001. Minimax Play at Wimbledon. The American Economic Review, 91(5) (Dec.): 1521-1538.

[33] Woodland, B., and L. Woodland, L. 1999. Expected utility, skewness and the baseball betting market. Applied Economics, 31: 337-345. 


\section{Appendix}

\subsection{Combined Shadow and Spillover Effects}

Our main analysis considers separately the effects of effort spillover and the shadow of future competition. Here, we present an analysis when both effects are at play. Moreover, we allow spillover to be an increasing function of first-stage effort. Combining the effects does not change the general predictions of the previous analysis - the prospect of a stronger future competitor, as well as the presence of negative spillover, continue to even the playing field.

\subsubsection{Spillover and Shadow - Final Stage}

Our first order condition for the final stage yields equilibrium effort choice

$$
x_{i}^{*}=\frac{\Delta V}{k\left(z_{i}\right) a c_{i}}
$$

where $k(\cdot)$ reflects the degree of spillover from the previous stage and is a strictly increasing function of first stage effort $z_{i}$. As expected, greater first-stage effort results in lower effort in the final stage. Further, this effect is amplified for the stronger type since $c_{1}<c_{2}$. The final stage spillover effect is

$$
\frac{\partial x_{i}^{*}}{\partial k\left(z_{i}\right)}=\frac{-\Delta V}{k\left(z_{i}\right)^{2} a c_{i}}<0
$$

Therefore, a common level of spillover reduces the disparity between participants' efforts in the final stage, since $\frac{\partial x_{1}^{*}}{\partial k\left(z_{1}\right)}<\frac{\partial x_{2}^{*}}{\partial k\left(z_{2}\right)}<0$. As a result, the stronger player is less likely to win in the final stage.

\subsubsection{Spillover and Shadow - First Stage}

Next, we consider effort decisions in the first stage. We write $k\left(z_{i}\right)$ as $k_{i}$ to simplify the notation in this section and express player $i$ 's payoff as

$$
\pi_{i}=G_{\text {first }}(\cdot)\left(\left(\frac{\frac{\Delta V}{k_{i} a c_{i}}-\frac{\Delta V}{k_{j} a c_{j}}+\frac{a}{2}}{a}\right) \Delta V-\frac{1}{2} k_{i} c_{i}\left(\frac{\Delta V}{k_{i} a c_{i}}\right)^{2}+V_{L}\right)-\frac{1}{2} c_{i} z_{i}^{2}
$$


The first order condition for the first stage is

$$
\frac{\partial \pi_{i}}{\partial z_{i}=\frac{\left(\frac{\frac{\Delta V}{k_{i} a c_{i}}-\frac{\Delta V}{k_{j} a c_{j}}+\frac{a}{2}}{a}\right) \Delta V-\frac{1}{2} k_{i} c_{i}\left(\frac{\Delta V}{k_{i} a c_{i}}\right)^{2}+V_{L}}{a}} \begin{aligned}
& \\
& +G_{f i r s t}(\cdot)\left(-\frac{\Delta V^{2}}{2 k_{i}^{2} a^{2} c_{i}}\right) \frac{\partial k_{i}}{\partial z_{i}}-c_{i} z_{i}=0
\end{aligned}
$$

which then gives us the following expression for first-stage equilibrium effort:

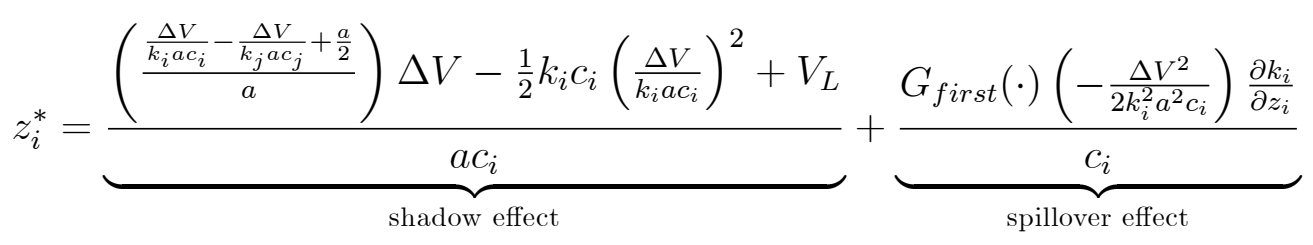

With no spillover, the left term is the shadow effect that we described in Section (1.2). The right term reflects spillover.

Consider the effect of introducing spillover. Since $G_{f i r s t}(\cdot) \geq \frac{1}{2}$ and $c_{1}<c_{2}$, the negative spillover effect is greater in magnitude for the stronger player. This increases the chances that the weaker player wins; thus, spillover has the effect of evening the playing field. That is, ceteris paribus, spillover increases the chance of an upset.

\subsection{A General Distribution Case}

The model in the body of the paper presents results when the noise in players' output is distributed uniformly; recall that, in Section (1), we define $\varepsilon=\varepsilon_{3}-\varepsilon_{1}$ and assume that $\varepsilon$ is distributed according to $G \sim U\left[-\frac{1}{2} a, \frac{1}{2} a\right]$. In fact, similar results can be derived for any unimodal and symmetric distribution $G(\cdot)$ with mean zero. Again assume that the firststage matches are resolved sequentially; players 1 and 2 know that player 3 won his parallel match to advance to the final stage.

Player 1's payoff function for the final stage can be written as

$$
\pi_{1, \text { final }}=G\left(x_{1}-x_{3}\right) \Delta V-\frac{1}{2} c_{1}\left(x_{1}\right)^{2}+V_{L}
$$

and his first order condition is

$$
\frac{\partial \pi_{1, f i n a l}}{\partial x_{1}}=G^{\prime}\left(x_{1}-x_{3}\right) \Delta V-c_{1} x_{1}=0
$$


Similarly, player 3's first order condition is

$$
G^{\prime}\left(x_{3}-x_{1}\right) \Delta V-c_{3} x_{3}=0
$$

Since $G(\cdot)$ is symmetric about its mean, it follows that $G^{\prime}\left(x_{1}-x_{3}\right)=G^{\prime}\left(x_{3}-x_{1}\right)$. This implies the following in equilibrium:

$$
\frac{x_{1}^{*}}{x_{3}^{*}}=\frac{c_{3}}{c_{1}}
$$

Although changes in the prize spread or the noise around players' output affect equilibrium effort, the ratio of players' efforts is constant. It follows, for example, that an increase in the prize spread that leads to higher equilibrium effort from both competitors will necessarily increase the absolute spread between players' efforts. In turn, this increases the probability that the stronger player wins in the current stage since his probability of winning is $G\left(x_{1}-x_{3}\right)$. In contrast, as equilibrium effort falls - for example, from the adverse effects of negative spillover - the absolute spread between players' efforts decreases. Here, the probability that the stronger player wins declines with equilibrium effort levels.

Since $G(\cdot)$ can be any unimodal symmetric distribution, the impact of changes in the variance of $G(\cdot)$ depends on the exact distribution and its parameters. The top panel of Figure A1 provides an illustration of two PDFs of $G(\cdot)$, both normal distributions centered at zero with standard deviations of 1 and 2, respectively.

First consider region A. When the players are relatively similar in ability and thus choose similar equilibrium efforts, reducing the variance means a "thickening" of the density. This provides greater incentives for both players, as the marginal return to effort is greater. Therefore, when players are similar in ability, the probability that the stronger player wins increases as the variance decreases.

Now consider region B in which the ability difference between players is substantial and decreased variance means a "thinning" of the density. This weakens incentives for both players, as the marginal return to effort is reduced. Therefore, in this region, decreased variance reduces the probability that the stronger player wins.

\subsection{Shadow Effect}

To study the impact of a change in the ability of the future competitor on first-stage outcomes, we consider the case where player 3 becomes a stronger opponent (i.e., $c_{3}$ decreases). Two inequalities are sufficient for player 1 to weakly decrease his effort relative to his current opponent's effort and thus reduces his probability of winning in the first stage: (a) $G^{\prime}\left(x_{1}^{*}-x_{3}^{*}\right) \geq G^{\prime}\left(x_{2}^{*}-x_{3}^{*}\right)$ and (b) $G^{\prime \prime}\left(x_{1}^{*}-x_{3}^{*}\right) \geq G^{\prime \prime}\left(x_{2}^{*}-x_{3}^{*}\right)$. 
When noise is distributed uniformly, both of these weak inequalities hold. For more general distributions, we must analyze these inequalities over several cases. Consider a contest where $\varepsilon$, the difference in players' additive noise terms, is drawn from a normal distribution, illustrated in the bottom panel of Figure A1. Since the ordering of players' efforts is critical for the analysis, we outline three cases.

Inequality (a): $G^{\prime}\left(x_{1}^{*}-x_{3}^{*}\right) \geq G^{\prime}\left(x_{2}^{*}-x_{3}^{*}\right)$

Ordering 1) When $x_{3}^{*}<x_{2}^{*}<x_{1}^{*}$, players 1 and 2 expect to face a future opponent who is weaker than both of them. For example, in the bottom panel of Figure A1, suppose that $x_{1}^{*}-x_{3}^{*}$ lies at $\mathrm{E}$ and $x_{2}^{*}-x_{3}^{*}$ lies between $\mathrm{D}$ and $\mathrm{E}$. Here, we violate inequality (a). However, if player 1 and 2 are sufficiently similar in ability, the increase in player 1's effort can still be greater despite a smaller change in his continuation value since $c_{1}<c_{2}$.

Ordering 2) When $x_{2}^{*}<x_{1}^{*}<x_{3}^{*}$, the future opponent is always stronger than both current players. In this case, it is unambiguous that the stronger player has a greater increase of effort. For example, when $x_{1}^{*}-x_{3}^{*}$ lies between $\mathrm{C}$ and $\mathrm{D}$ and $x_{2}^{*}-x_{3}^{*}$ is to the left of that, we find that $G^{\prime}\left(x_{1}-x_{3}\right)>G^{\prime}\left(x_{2}-x_{3}\right)$.

Ordering 3) When $x_{2}^{*}<x_{3}^{*}<x_{1}^{*}$, the future opponent is stronger than player 2, but weaker than player 1 . When $x_{1}^{*}-x_{3}^{*}>\left|x_{2}^{*}-x_{3}^{*}\right|$, inequality (a) is violated. However, when $x_{1}^{*}-x_{3}^{*} \leq\left|x_{2}^{*}-x_{3}^{*}\right|$, inequality (a) is satisfied. In Figure A1, inequality (a) is satisfied when $x_{1}^{*}-x_{3}^{*}$ falls between $\mathrm{D}$ and $\mathrm{E}$ and $x_{2}^{*}-x_{3}^{*}$ falls below $\mathrm{C}$.

Inequality (b): $G^{\prime \prime}\left(x_{1}^{*}-x_{3}^{*}\right) \geq G^{\prime \prime}\left(x_{2}^{*}-x_{3}^{*}\right)$

To analyze the impact of a change in the future opponent, we focus on the continuation value in the first stage. ${ }^{26}$ Recall that

$$
\pi_{i, \text { final }}=\widetilde{V}_{i}=G\left(x_{i}-x_{3}\right) \Delta V-\frac{1}{2} c_{i}\left(x_{i}\right)^{2}+V_{L}
$$

so that

$$
\frac{\partial \widetilde{V}_{i}}{\partial c_{3}}=-\frac{\partial x_{3}^{*}}{\partial c_{3}} G^{\prime}\left(x_{i}^{*}-x_{3}^{*}\right) \Delta V>0
$$

where, using the implicit function theorem,

$$
\left.\frac{\partial x_{3}}{\partial c_{3}}\right|_{F O C, i}=\frac{x_{3}^{*}}{G^{\prime \prime}\left(x_{3}^{*}-x_{i}^{*}\right) \Delta V-c_{3}}<0 .
$$

Thus, the magnitude of $\frac{\partial x_{3}^{*}}{\partial c_{3}}$ depends on $G^{\prime \prime}(\cdot)$, the slope of $G^{\prime}(\cdot)$. The denominator of this expression is the SOC and, therefore, is negative.

Again, we consider the three cases.

\footnotetext{
${ }^{26}$ Note that $G^{\prime}\left(z_{1}-z_{2}\right)=G^{\prime}\left(z_{2}-z_{1}\right)$ in the FOCs.
} 
Ordering 1) When $x_{3}^{*}<x_{2}^{*}<x_{1}^{*}$, it is ambiguous whether the inequality holds. When player 3 is worse than both 1 and $2, x_{3}^{*}-x_{1}^{*}$ and $x_{3}^{*}-x_{2}^{*}$ both lie on the left-hand-side of the PDF. Although both slopes are always positive, there are cases where $G^{\prime \prime}\left(x_{3}^{*}-x_{2}^{*}\right)<$ $G^{\prime \prime}\left(x_{3}^{*}-x_{1}^{*}\right)$ and other cases where $G^{\prime \prime}\left(x_{3}^{*}-x_{2}^{*}\right)>G^{\prime \prime}\left(x_{3}^{*}-x_{1}^{*}\right)$.

Ordering 2) When $x_{2}^{*}<x_{1}^{*}<x_{3}^{*}$, it is likely that the inequality holds. For this case, $x_{3}^{*}-x_{1}^{*}$ and $x_{3}^{*}-x_{2}^{*}$ both lie on the right-hand side of the PDF. The inequality holds ambiguously in regions in which the PDF is concave in its argument for both $x_{3}^{*}-x_{1}^{*}$ and $x_{3}^{*}-x_{2}^{*}$. For the normal distribution in the lower panel of Figure A1, this occurs when both $x_{3}^{*}-x_{1}^{*}$ and $x_{3}^{*}-x_{2}^{*}$ lie to the right of the peak and left of the inflection point. When the differences both fall to the right of the inflection point, the reverse is true. When $x_{3}^{*}-x_{1}^{*}$ and $x_{3}^{*}-x_{2}^{*}$ fall on different sides of the inflection point, the result is ambiguous. In short, as long as $x_{3}^{*}$ is sufficiently similar to $x_{1}^{*}$, the inequality holds.

Ordering 3) When $x_{2}^{*}<x_{3}^{*}<x_{1}^{*}$, the inequality is always satisfied. Since $x_{3}^{*}-x_{1}^{*}$ and $x_{3}^{*}-x_{2}^{*}$ are located on the left- and right-hand sides of the PDF, respectively, $G^{\prime \prime}\left(x_{3}^{*}-x_{1}^{*}\right)>0$ and $G^{\prime \prime}\left(x_{3}^{*}-x_{2}^{*}\right)<0$.

In summary, the intersection of both inequalities requires that the future opponent player 3 be not too much less skilled than player 1. Assuming that the spreads between players' abilities are similar across parallel matches, we will observe most often the case where the expected future opponent is more similar in ability to the stronger current player (relative to the weaker current player). Therefore, the shadow effect is expected in the typical scenarios in which player 3 is either slightly better than both 1 and 2; or worse than player 1 but more similar in skill to player 1 than player 2. For cases in which player 3 is either much worse or much better than the current players, the presence of a shadow effect is possible but not assured by the theory. Empirically, the presence of such ambiguous cases should reduce our ability to identify any shadow effect in the data.

\subsection{Spillover}

In the section (1.3), we describe negative spillover as increasing players' effective cost types. Assume that two players experience the same level of exertion in the first stage, leading to the same proportional increase in cost types in the final stage. The ratio of their efforts remains unchanged; however, final stage efforts are lower and thus the absolute spread in efforts is smaller, and the stronger player is less likely to win the match. Therefore, as we found in the uniform case, spillover evens the playing field. 
Figure 1 - Example Draw from 2007 Davidoff Swiss Indoors in Basel

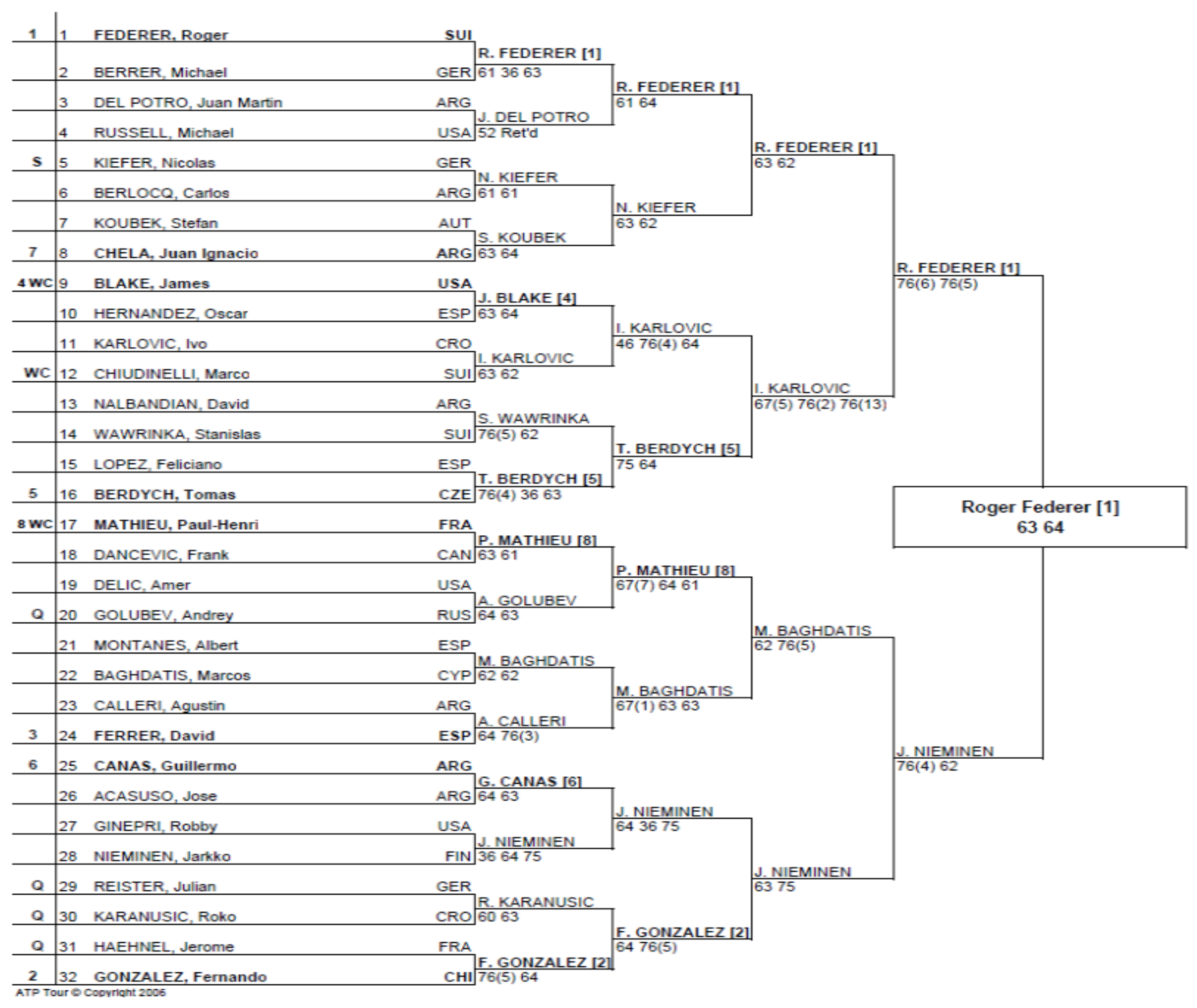

Source: ATPworldtour.com 
Table 1 - Summary Statistics for ATP World Tour Events (January 2001 to May 2010)

\section{Five Round Tournaments}

\# of Matches Played

All Rounds 1st Round 2nd Round Quarterfinals Semifinals The Final

Games Per Match

13288

6807

3456

1729

864

432

$\begin{array}{cccccc}22.4 & 22.2 & 22.4 & 22.5 & 22.7 & 23.8 \\ (6.4) & (6.1) & (6.6) & (6.5) & (6.6) & (7.2) \\ 5.8 & 5.3 & 6.8 & 5.6 & 5.7 & 6.5 \\ (15.6) & (13.7) & (21.2) & (10.7) & (11.8) & (14.6) \\ 70.3 & 84.1 & 62.5 & 52.7 & 45.1 & 37.0 \\ (78.2) & (91.2) & (60.5) & (57.2) & (53.2) & (42.8) \\ 110.1 & 132.8 & 104.0 & 72.3 & 60.3 & 53.2 \\ (135.0) & (162.6) & (109.5) & (62.3) & (60.0) & (60.8)\end{array}$

\section{Six Round Tournaments}

\# of Matches Played

\begin{tabular}{ccccccc} 
All Rounds & 1st Round & 2nd Round & 3rd Round & Quarterfinals & Semifinals & The Final \\
\hline 6943 & 2952 & 2056 & 1032 & 516 & 258 & 129
\end{tabular}

Games Per Match

6943

2952

258

129

22.6

(6.4)

22.4

22.8

(6.2)

22.4

22.5

22.9

26.7

6.7

(6.2)

(6.7)

(6.6)

(6.5)

(9.3)

(20.5)

(12.8)

(19.2)

9.5

8.4

6.8

52.2

73.2

44.0

(18.9)

(48.5)

(14.2)

(9.6)

(70.2)

(57.9)

34.1

26.6

20.8

14.4

77.0

$(83.9)$

(51.8)

(39.3)

(36.4)

(20.9)

(106.4)

(133.8)

(87.8)

(62.4)

(59.6)

(41.2)

(30.9)

\section{Seven Round Tournaments}

\# of Matches Played

\begin{tabular}{ccccccc} 
All Rounds & 1st Round & 2nd Round & 3rd Round & 4th Round Quarterfinals Semifinals & The Final \\
\hline
\end{tabular}

Games Per Match

$\begin{array}{ccc}6314 & 2913 & 1725 \\ & & \\ 32.0 & 32.6 & 31.1 \\ (10.8) & (10.5) & (10.9) \\ 9.1 & 7.8 & 10.6 \\ (29.1) & (37.3) & (20.9) \\ 50.8 & 71.1 & 42.7 \\ (69.7) & (75.8) & (62.9) \\ 85.4 & 110.6 & 82.8 \\ (99.3) & (118.5) & (75.0)\end{array}$

865

433

216

108

54

Rank Ratio

31.7

$(11.1)$

$$
31.7
$$

(11.5)

32.1

31.9

(11.2)

34.1

9.9

10.4

(11.9)

9.0

(11.8)

(18.8)

(20.1)

(11.9)

(15.5)

$\begin{array}{lll}30.7 & 21.5 & 13.0\end{array}$

(58.4)

(57.3)

(19.3)

11.5

(10.9)

55.7

39.9

29.9

(19.9)

7.0

(66.7)

(58.1)

(77.9)

14.5

(18.0)

(18.7)

(20.8)

Notes: Data contain player and performance information for 615 tournaments. We exclude 212 five-round, 2352 six-round, and 1086 seven-round matches in which a player advanced with a bye. Values in parentheses are standard deviations. "Rank Ratio" is calculated from players' current ranks: worse rank divided by better rank. 
Table 2 - Spillover and Shadow Effects

Dependent Variable:

Five Round Events

Expected Future

Opponent Rank

Stronger Player's

Previous Games

Weaker Player's

Previous Games

Current Rank Ratio

(Worse / Better Rank)

\# of observations

Six Round Events

Expected Future

Opponent Rank

Stronger Player's

Previous Games

Weaker Player's

Previous Games

Current Rank Ratio

(Worse / Better Rank)

\# of observations

Seven Round Events

Expected Future

Opponent Rank

Stronger Player's

Previous Games

Weaker Player's

Previous Games

Current Rank Ratio

(Worse / Better Rank)

\# of observations

Stronger Player Wins in Current Period (0\% or 100\%)

\begin{tabular}{|c|c|c|c|c|}
\hline $\begin{array}{c}\text { 2nd on } \\
\text { 1st Round }\end{array}$ & $\begin{array}{l}\text { Qfinals on } \\
\text { 2nd Round }\end{array}$ & $\begin{array}{c}\text { Sfinals on } \\
\text { Qfinals }\end{array}$ & $\begin{array}{c}\text { Final on } \\
\text { Sfinals } \\
\end{array}$ & $\begin{array}{c}\text { The Final } \\
\text { (no shadow) }\end{array}$ \\
\hline \multirow[t]{3}{*}{$\begin{array}{l}0.0546^{* * *} \\
(0.0130)\end{array}$} & $\begin{array}{l}0.0828 * * * \\
(0.0255)\end{array}$ & $\begin{array}{l}0.0522 \\
(0.0471)\end{array}$ & $\begin{array}{l}0.0652 \\
(0.0654)\end{array}$ & \\
\hline & $\begin{array}{l}-0.4404 * * * \\
(0.1184)\end{array}$ & $\begin{array}{l}-0.2255^{*} \\
(0.1231)\end{array}$ & $\begin{array}{l}-0.1562 * \\
(0.0874)\end{array}$ & $\begin{array}{l}-0.2639 * * \\
(0.1169)\end{array}$ \\
\hline & $\begin{array}{l}0.0654 \\
(0.1278)\end{array}$ & $\begin{array}{l}0.1399 \\
(0.1250)\end{array}$ & $\begin{array}{l}0.1421 \\
(0.0932)\end{array}$ & $\begin{array}{l}0.1613 \\
(0.1217)\end{array}$ \\
\hline $\begin{array}{l}0.3427 * * * \\
(0.0704)\end{array}$ & $\begin{array}{l}0.2071 * * * \\
(0.0503)\end{array}$ & $\begin{array}{l}0.2964 * * \\
(0.1195)\end{array}$ & $\begin{array}{l}0.6044 * * * \\
(0.1718)\end{array}$ & $\begin{array}{l}0.2049 \\
(0.3072)\end{array}$ \\
\hline 6749 & 3435 & 1718 & 856 & 432 \\
\hline
\end{tabular}

\begin{tabular}{|c|c|c|c|c|c|}
\hline $\begin{array}{c}\text { 2nd on } \\
\text { 1st Round }\end{array}$ & $\begin{array}{c}\text { 3rd on } \\
\text { 2nd Round }\end{array}$ & $\begin{array}{l}\text { Qfinals on } \\
\text { 3rd Round }\end{array}$ & $\begin{array}{c}\text { Sfinals on } \\
\text { Qfinals }\end{array}$ & $\begin{array}{c}\text { Final on } \\
\text { Sfinals }\end{array}$ & $\begin{array}{c}\text { The Final } \\
\text { (no shadow) }\end{array}$ \\
\hline \multirow[t]{3}{*}{$\begin{array}{l}0.0531 \\
(0.0351)\end{array}$} & $\begin{array}{l}0.0771 \\
(0.0486)\end{array}$ & $\begin{array}{l}0.1363 * * \\
(0.0683)\end{array}$ & $\begin{array}{l}0.0686 \\
(0.1175)\end{array}$ & $\begin{array}{l}0.2351 \\
(0.2472)\end{array}$ & \\
\hline & $\begin{array}{l}-0.2141^{*} \\
(0.1227)\end{array}$ & $\begin{array}{l}-0.3893 * * * \\
(0.1301)\end{array}$ & $\begin{array}{l}-0.5252 * * * \\
(0.1532)\end{array}$ & $\begin{array}{l}-0.2452 * * * \\
(0.0790)\end{array}$ & $\begin{array}{l}-0.0329 \\
(0.1276)\end{array}$ \\
\hline & $\begin{array}{l}0.3198 * * \\
(0.1551)\end{array}$ & $\begin{array}{l}0.1317 \\
(0.1345)\end{array}$ & $\begin{array}{l}0.3091^{* *} \\
(0.1523)\end{array}$ & $\begin{array}{l}0.1085 \\
(0.0715)\end{array}$ & $\begin{array}{l}0.0452 \\
(0.0983)\end{array}$ \\
\hline $\begin{array}{l}0.2730 * * * \\
(0.0767)\end{array}$ & $\begin{array}{l}0.3001 * * * \\
(0.0795)\end{array}$ & $\begin{array}{l}0.2632 * * * \\
(0.0827)\end{array}$ & $\begin{array}{l}0.0478 * * * \\
(0.0166)\end{array}$ & $\begin{array}{l}0.6464 * * * \\
(0.1817)\end{array}$ & $\begin{array}{l}1.0254^{*} \\
(0.5269)\end{array}$ \\
\hline 2923 & 2043 & 1029 & 516 & 256 & 129 \\
\hline
\end{tabular}

\begin{tabular}{|c|c|c|c|c|c|c|}
\hline $\begin{array}{c}\text { 2nd on } \\
1 \text { st Round }\end{array}$ & $\begin{array}{c}\text { 3rd on } \\
\text { 2nd Round }\end{array}$ & $\begin{array}{c}\text { 4th on } \\
\text { 3rd Round }\end{array}$ & $\begin{array}{l}\text { Qfinals on } \\
\text { 4th Round }\end{array}$ & $\begin{array}{c}\text { Sfinals on } \\
\text { Qfinals }\end{array}$ & $\begin{array}{c}\text { Final on } \\
\text { Sfinals } \\
\end{array}$ & $\begin{array}{c}\text { The Final } \\
\text { (no shadow) }\end{array}$ \\
\hline \multirow[t]{3}{*}{$\begin{array}{l}0.1737 * * * \\
(0.0256)\end{array}$} & $\begin{array}{l}0.1124 * * \\
(0.0507)\end{array}$ & $\begin{array}{l}0.1646^{* *} \\
(0.0754)\end{array}$ & $\begin{array}{l}0.4485^{* * *} \\
(0.1435)\end{array}$ & $\begin{array}{l}0.0865 \\
(0.2946)\end{array}$ & $\begin{array}{l}0.0900 \\
(0.7264)\end{array}$ & \\
\hline & $\begin{array}{l}-0.5882 * * * \\
(0.1463)\end{array}$ & $\begin{array}{l}-0.4423 * * * \\
(0.1324)\end{array}$ & $\begin{array}{l}-0.2482 \\
(0.1582)\end{array}$ & $\begin{array}{l}-0.2216 \\
(0.1551)\end{array}$ & $\begin{array}{l}-0.1301^{* *} \\
(0.0631)\end{array}$ & $\begin{array}{l}-0.1048 \\
(0.1178)\end{array}$ \\
\hline & $\begin{array}{l}0.1676 \\
(0.1186)\end{array}$ & $\begin{array}{l}0.1100 \\
(0.1088)\end{array}$ & $\begin{array}{l}0.1289 \\
(0.1127)\end{array}$ & $\begin{array}{l}-0.0670 \\
(0.1653)\end{array}$ & $\begin{array}{l}0.0367 \\
(0.0547)\end{array}$ & $\begin{array}{l}0.0469 \\
(0.0777)\end{array}$ \\
\hline $\begin{array}{l}0.0859^{* * *} \\
(0.0327)\end{array}$ & $\begin{array}{l}0.2601 * * * \\
(0.0446)\end{array}$ & $\begin{array}{l}0.3397 * * * \\
(0.0641)\end{array}$ & $\begin{array}{l}0.3365^{* * *} \\
(0.0846)\end{array}$ & $\begin{array}{l}0.3309 \\
(0.3138)\end{array}$ & $\begin{array}{l}0.0132 \\
(0.3482)\end{array}$ & $\begin{array}{l}1.2632 * * \\
(0.5448)\end{array}$ \\
\hline 2903 & 1716 & 858 & 432 & 216 & 108 & 54 \\
\hline
\end{tabular}

Notes: Values in parentheses are robust standard errors. All regressions include tournament-level fixed effects. Column labels identify the round and the shadow effect being analyzed. For example, "2nd on 1st Round" uses match observations from the first round of a tournament and considers the shadow of the expected second round opponent on first round outcomes.

$* p<0.10, * * p<0.05, * * * p<0.01$ 
Table 3 - Spillover and Shadow Effects (only matches with previous resolution)

Dependent Variable:

Five Round Events

Expected Future

Opponent Rank

Stronger Player's

Previous Games

Weaker Player's

Previous Games

Current Rank Ratio

(Worse / Better Rank)

\# of observations

Six Round Events

Expected Future

Opponent Rank

Stronger Player's

Previous Games

Current Rank Ratio

(Worse / Better Rank)

\# of observations

Seven Round Events

Expected Future

Opponent Rank

Stronger Player's

Previous Games

Weaker Player's

Previous Games

Current Rank Ratio

(Worse / Better Rank)

\# of observations
Previous Games

Weaker Player's

Stronger Player Wins in Current Period (0\% or 100\%)

\begin{tabular}{|c|c|c|c|}
\hline $\begin{array}{c}\text { 2nd on } \\
\text { 1st Round }\end{array}$ & $\begin{array}{l}\text { Qfinals on } \\
\text { 2nd Round }\end{array}$ & $\begin{array}{c}\text { Sfinals on } \\
\text { Qfinals }\end{array}$ & $\begin{array}{c}\text { Final on } \\
\text { Sfinals }\end{array}$ \\
\hline \multirow[t]{3}{*}{$\begin{array}{l}0.0205 \\
(0.0219)\end{array}$} & $\begin{array}{l}0.0854 \\
(0.1132)\end{array}$ & $\begin{array}{l}0.2633 \\
(0.2847)\end{array}$ & $\begin{array}{l}-0.3530 \\
(0.3230)\end{array}$ \\
\hline & $\begin{array}{l}-0.8412 * * \\
(0.3337)\end{array}$ & $\begin{array}{l}-0.4769 \\
(0.6800)\end{array}$ & $\begin{array}{l}-0.2094 \\
(0.5140)\end{array}$ \\
\hline & $\begin{array}{l}0.7356 \\
(0.4567)\end{array}$ & $\begin{array}{l}0.2783 \\
(0.7626)\end{array}$ & $\begin{array}{l}-0.2250 \\
(0.6243)\end{array}$ \\
\hline $\begin{array}{l}0.3981 * * * \\
(0.0854)\end{array}$ & $\begin{array}{l}0.3906 * * * \\
(0.1170)\end{array}$ & $\begin{array}{l}1.1498 \\
(1.0486)\end{array}$ & $\begin{array}{l}1.5529 \\
(1.6900)\end{array}$ \\
\hline 1354 & 295 & 81 & 51 \\
\hline
\end{tabular}

\begin{tabular}{|c|c|c|c|c|}
\hline $\begin{array}{c}\text { 2nd on } \\
\text { 1st Round }\end{array}$ & $\begin{array}{c}\text { 3rd on } \\
\text { 2nd Round }\end{array}$ & $\begin{array}{l}\text { Qfinals on } \\
\text { 3rd Round }\end{array}$ & $\begin{array}{c}\text { Sfinals on } \\
\text { Qfinals }\end{array}$ & $\begin{array}{c}\text { Final on } \\
\text { Sfinals } \\
\end{array}$ \\
\hline \multirow[t]{3}{*}{$\begin{array}{l}0.0569 \\
(0.1343)\end{array}$} & $\begin{array}{l}-0.2871 \\
(0.2370)\end{array}$ & $\begin{array}{l}0.2784 \\
(0.2031)\end{array}$ & $\begin{array}{l}0.1969 \\
(0.8733)\end{array}$ & $\begin{array}{l}0.6962 \\
(0.5444)\end{array}$ \\
\hline & $\begin{array}{l}-0.5328 \\
(0.4715)\end{array}$ & $\begin{array}{l}-0.4109 \\
(1.0078)\end{array}$ & $\begin{array}{l}0.4002 \\
(1.3651)\end{array}$ & $\begin{array}{l}-0.2637 \\
(0.2699)\end{array}$ \\
\hline & $\begin{array}{l}-0.4236 \\
(0.4493)\end{array}$ & $\begin{array}{l}-0.6504 \\
(0.6811)\end{array}$ & $\begin{array}{l}-0.3203 \\
(1.4190)\end{array}$ & $\begin{array}{l}0.1490 \\
(0.2014)\end{array}$ \\
\hline $\begin{array}{l}0.2956 * * \\
(0.1239)\end{array}$ & $\begin{array}{l}0.7810^{* * * *} \\
(0.2372)\end{array}$ & $\begin{array}{l}1.6846 \\
(1.0301)\end{array}$ & $\begin{array}{l}3.5665^{* *} \\
(1.4181)\end{array}$ & $\begin{array}{l}2.7432 \\
(2.3072)\end{array}$ \\
\hline 272 & 182 & 37 & 16 & 21 \\
\hline
\end{tabular}

\begin{tabular}{|c|c|c|c|c|c|}
\hline $\begin{array}{c}\text { 2nd on } \\
\text { 1st Round }\end{array}$ & $\begin{array}{c}\text { 3rd on } \\
\text { 2nd Round }\end{array}$ & $\begin{array}{c}\text { 4th on } \\
\text { 3rd Round }\end{array}$ & $\begin{array}{l}\text { Qfinals on } \\
\text { 4th Round }\end{array}$ & $\begin{array}{c}\text { Sfinals on } \\
\text { Qfinals }\end{array}$ & $\begin{array}{c}\text { Final on } \\
\text { Sfinals } \\
\end{array}$ \\
\hline $\begin{array}{l}-0.0208 \\
(0.1139)\end{array}$ & $\begin{array}{l}0.0249 \\
(0.2993)\end{array}$ & $\begin{array}{l}0.4790 * * * \\
(0.1716)\end{array}$ & $\begin{array}{l}0.3028 \\
(0.8503)\end{array}$ & $\begin{array}{l}-0.7066 \\
(1.4330)\end{array}$ & $\begin{array}{l}0.5434 \\
(1.5524)\end{array}$ \\
\hline
\end{tabular}

Notes: Values in parentheses are robust standard errors. All regressions include tournament-level fixed effects. Column labels identify the round and the shadow effect being analyzed. For example, "2nd on 1st Round" uses match observations from the first round of a tournament and considers the shadow of the expected second round opponent on first round outcomes. Final round data have been omitted because there is no shadow.

$* p<0.10, * * p<0.05, * * * p<0.01$ 
Table 4 - Spillover and Shadow Effects with Long Shadow

Dependent Variable:

Five Round Events

Expected Future

Opponent Rank

Best Player Rank

Stronger Player's

Previous Games

Weaker Player's

Previous Games

Current Rank Ratio

(Worse / Better Rank)

\# of observations

Six Round Events

Expected Future

Opponent Rank

Best Player Rank

Stronger Player's

Previous Games

Weaker Player's

Previous Games

Current Rank Ratio

(Worse / Better Rank)

\# of observations

Seven Round Events

Expected Future

Opponent Rank

Best Player Rank

Stronger Player's

Previous Games

Weaker Player's

Previous Games

Current Rank Ratio (Worse / Better Rank)

\# of observations
Stronger Player Wins in Current Period ( $0 \%$ or $100 \%)$

\begin{tabular}{|c|c|c|c|c|}
\hline $\begin{array}{c}\text { 2nd on } \\
\text { 1st Round }\end{array}$ & $\begin{array}{l}\text { Qfinals on } \\
\text { 2nd Round }\end{array}$ & $\begin{array}{c}\text { Sfinals on } \\
\text { Qfinals }\end{array}$ & $\begin{array}{c}\text { Final on } \\
\text { Sfinals }\end{array}$ & $\begin{array}{c}\text { The Final } \\
\text { (no shadow) }\end{array}$ \\
\hline $\begin{array}{l}0.0512 * * * \\
(0.0131)\end{array}$ & $\begin{array}{l}0.0782 * * * \\
(0.0257)\end{array}$ & $\begin{array}{l}0.0305 \\
(0.0480)\end{array}$ & $\begin{array}{l}0.0066 \\
(0.0719)\end{array}$ & \\
\hline \multirow[t]{3}{*}{$\begin{array}{l}0.2602 * * * \\
(0.0959)\end{array}$} & $\begin{array}{l}0.1637 \\
(0.1252)\end{array}$ & $\begin{array}{l}0.4334 * * \\
(0.1806)\end{array}$ & $\begin{array}{l}0.6987 * * * \\
(0.2567)\end{array}$ & $\begin{array}{l}-0.6221^{*} \\
(0.3571)\end{array}$ \\
\hline & $\begin{array}{l}-0.4314 * * * \\
(0.1187)\end{array}$ & $\begin{array}{l}-0.2101^{*} \\
(0.1229)\end{array}$ & $\begin{array}{l}-0.1516^{*} \\
(0.0869)\end{array}$ & $\begin{array}{l}-0.2676^{* *} \\
(0.1177)\end{array}$ \\
\hline & $\begin{array}{l}0.0683 \\
-0.1277\end{array}$ & $\begin{array}{l}0.1491 \\
-0.1243\end{array}$ & $\begin{array}{l}0.1542 * \\
-0.0925\end{array}$ & $\begin{array}{l}0.1454 \\
-0.1222\end{array}$ \\
\hline $\begin{array}{l}0.3412 * * * \\
(0.0698)\end{array}$ & $\begin{array}{l}0.2053^{* * *} \\
(0.0497)\end{array}$ & $\begin{array}{l}0.2884 * * \\
(0.1180)\end{array}$ & $\begin{array}{l}0.5949 * * * \\
(0.1771)\end{array}$ & $\begin{array}{l}0.2352 \\
(0.3124)\end{array}$ \\
\hline 6749 & 3435 & 1718 & 856 & 432 \\
\hline
\end{tabular}

\begin{tabular}{|c|c|c|c|c|c|}
\hline $\begin{array}{c}\text { 2nd on } \\
\text { 1st Round }\end{array}$ & $\begin{array}{c}\text { 3rd on } \\
\text { 2nd Round }\end{array}$ & $\begin{array}{l}\text { Qfinals on } \\
\text { 3rd Round }\end{array}$ & $\begin{array}{c}\text { Sfinals on } \\
\text { Qfinals }\end{array}$ & $\begin{array}{c}\text { Final on } \\
\text { Sfinals }\end{array}$ & $\begin{array}{l}\text { The Final } \\
\text { (no shadow) }\end{array}$ \\
\hline $\begin{array}{l}0.0553 \\
(0.0351)\end{array}$ & $\begin{array}{l}0.0785 \\
(0.0492)\end{array}$ & $\begin{array}{l}0.1008 \\
(0.0680)\end{array}$ & $\begin{array}{l}0.0642 \\
(0.1187)\end{array}$ & $\begin{array}{l}0.0622 \\
(0.2424)\end{array}$ & \\
\hline \multirow[t]{3}{*}{$\begin{array}{l}-0.6181 \\
(0.5319)\end{array}$} & $\begin{array}{l}-0.1012 \\
(0.4903)\end{array}$ & $\begin{array}{l}2.4195 * * * \\
(0.5985)\end{array}$ & $\begin{array}{l}1.8834 * * \\
(0.8600)\end{array}$ & $\begin{array}{l}3.4625 * * * \\
(1.2878)\end{array}$ & $\begin{array}{l}1.3384 \\
(1.2744)\end{array}$ \\
\hline & $\begin{array}{l}-0.2150^{*} \\
(0.1227)\end{array}$ & $\begin{array}{l}-0.3811 * * * \\
(0.1304)\end{array}$ & $\begin{array}{l}-0.4696 * * * \\
(0.1560)\end{array}$ & $\begin{array}{l}-0.2343^{* * * *} \\
(0.0785)\end{array}$ & $\begin{array}{l}-0.0226 \\
(0.1296)\end{array}$ \\
\hline & $\begin{array}{l}0.3193 * * \\
(0.1552)\end{array}$ & $\begin{array}{l}0.1382 \\
(0.1328)\end{array}$ & $\begin{array}{l}0.3036^{* *} \\
(0.1512)\end{array}$ & $\begin{array}{l}0.1121 \\
(0.0693)\end{array}$ & $\begin{array}{l}0.0479 \\
(0.1000)\end{array}$ \\
\hline $\begin{array}{l}0.2737 * * * \\
(0.0769)\end{array}$ & $\begin{array}{l}0.3006 * * * \\
(0.0798)\end{array}$ & $\begin{array}{l}0.2368^{* * * *} \\
(0.0749)\end{array}$ & $\begin{array}{l}0.0436 * * * \\
(0.0161)\end{array}$ & $\begin{array}{l}0.5874 * * * \\
(0.1684)\end{array}$ & $\begin{array}{l}0.9409^{*} \\
(0.5255)\end{array}$ \\
\hline 2923 & 2043 & 1029 & 516 & 256 & 129 \\
\hline
\end{tabular}

\begin{tabular}{|c|c|c|c|c|c|c|}
\hline $\begin{array}{c}\text { 2nd on } \\
\text { 1st Round }\end{array}$ & $\begin{array}{c}\text { 3rd on } \\
\text { 2nd Round }\end{array}$ & $\begin{array}{c}\text { 4th on } \\
\text { 3rd Round }\end{array}$ & $\begin{array}{l}\text { Qfinals on } \\
\text { 4th Round }\end{array}$ & $\begin{array}{c}\text { Sfinals on } \\
\text { Qfinals }\end{array}$ & $\begin{array}{c}\text { Final on } \\
\text { Sfinals }\end{array}$ & $\begin{array}{l}\text { The Final } \\
\text { (no shadow) }\end{array}$ \\
\hline $\begin{array}{l}1730^{* * * *} \\
0.0256)\end{array}$ & $\begin{array}{l}0.1154^{* *} \\
(0.0506)\end{array}$ & $\begin{array}{l}0.1707 * * \\
(0.0754)\end{array}$ & $\begin{array}{l}0.4646^{* * *} \\
(0.1422)\end{array}$ & $\begin{array}{l}0.0811 \\
(0.3025)\end{array}$ & $\begin{array}{l}-0.5463 \\
(0.6909)\end{array}$ & \\
\hline
\end{tabular}

4.1255
$(3.6350)$

$8.8721^{* *} \quad 8.9734^{* *}$

$0.1422)$

$(0.3025)$

$(0.6909)$

$13.5353 * * * \quad 19.9171 * * * \quad 27.3365 * * * \quad 9.9441$

$\begin{array}{llll}(3.7688) & (4.3439) & (6.8427) & (9.1277)\end{array}$

$\begin{array}{lllll}(3.5463) & (3.7948) & (3.7688) & (4.3439) & (6.8427)\end{array}$

$-0.1171$

$\begin{array}{llllll}-0.5917 * * * & -0.4273 * * * & -0.2134 & -0.1402 & -0.0995 & -0.1171 \\ (0.1463) & (0.1326) & (0.1579) & (0.1562) & (0.0638) & (0.1200)\end{array}$

$(0.1463)$

$(0.1579)$

0.0575

$\begin{array}{llllll}0.1651 & 0.1151 & 0.1391 & 0.0054 & 0.0468 & 0.0575 \\ (0.1182) & (0.1087) & (0.1122) & (0.1662) & (0.0510) & (0.0784)\end{array}$

$\begin{array}{lllllll}0.0798 * * & 0.2095 * * * & 0.2850 * * * & 0.2598 * * * & 0.0558 & -0.1830 & 1.0372 * *\end{array}$

$\begin{array}{llllll}(0.0326) & (0.0525) & (0.0630) & (0.0745) & (0.2964) & (0.2833)\end{array}$

$\begin{array}{lllllll}2903 & 1716 & 858 & 432 & 216 & 108 & 54\end{array}$

Notes: Values in parentheses are robust standard errors. All regressions include tournament-level fixed effects. Column labels identify the round and the shadow effect being analyzed. For example, "2nd on 1st Round" uses match observations from the first round of a tournament and considers the shadow of the expected second round opponent on first round outcomes.

$* p<0.10, * * p<0.05, * * * p<0.01$ 
$\underline{\text { Table } 5 \text { - Summary Statistics for Betting Market (January } 2001 \text { to May 2010) }}$

Implied Probability that the Stronger Player Wins (\%)

All Rounds 1st Round 2nd Round 3rd Round 4th Round Quarterfinals Semifinals The Final

Five Round Tournaments

Six Round Tournaments

Seven Round Tournaments

$\begin{array}{ccc}68.1 & 67.6 & 69.6 \\ (14.8) & (15.5) & (14.4)\end{array}$

$\begin{array}{cccc}67.3 & 64.3 & 70.0 & 68.5 \\ (15.5) & (15.5) & (15.1) & (15.0)\end{array}$

$(15.5) \quad(15.5) \quad(15.1) \quad(15.0)$

$\begin{array}{cccc}71.4 & 68.9 & 74.5 & 72.0\end{array}$

(17.7)

(19.1)

(16.0)

(16.7)

71.7
$(16.8)$

67.6

(13.7)

69.0

(15.4)

73.8

(14.5)

$66.8 \quad 67.3$

(13.4) (13.3)

Notes: Data contain betting market information for 593 tournaments. Values in parentheses are standard deviations. 
Table 6 - Spillover and Shadow Effects in Betting Market

Dependent Variable:

Implied Probability that the Stronger Player Wins in Current Period (\%)

Five Round Events

Expected Future

Opponent Rank

Stronger Player's

Previous Games

Weaker Player's

Previous Games

Current Rank Ratio

(Worse / Better Rank)

\# of observations

Six Round Events

Expected Future

Opponent Rank

Stronger Player's

Previous Games

Weaker Player's

Previous Games

Current Rank Ratio

(Worse / Better Rank)

\# of observations

Seven Round Events

Expected Future

Opponent Rank

Stronger Player's

Previous Games

Weaker Player's

Previous Games

Current Rank Ratio

(Worse / Better Rank)

\# of observations

\begin{tabular}{|c|c|c|c|c|}
\hline $\begin{array}{c}\text { 2nd on } \\
\text { 1st Round }\end{array}$ & $\begin{array}{l}\text { Qfinals on } \\
\text { 2nd Round }\end{array}$ & $\begin{array}{c}\text { Sfinals on } \\
\text { Qfinals }\end{array}$ & $\begin{array}{c}\text { Final on } \\
\text { Sfinals }\end{array}$ & $\begin{array}{l}\text { The Final } \\
\text { (no shadow) }\end{array}$ \\
\hline \multirow[t]{3}{*}{$\begin{array}{l}0.0550 * * * \\
(0.0059)\end{array}$} & $\begin{array}{l}0.0419 * * * \\
(0.0076)\end{array}$ & $\begin{array}{l}0.0027 \\
(0.0129)\end{array}$ & $\begin{array}{l}0.0176 \\
(0.0172)\end{array}$ & \\
\hline & $\begin{array}{l}-0.3223 * * * \\
(0.0346)\end{array}$ & $\begin{array}{l}-0.1913 * * * \\
(0.0327)\end{array}$ & $\begin{array}{l}-0.1356^{* * *} \\
(0.0215)\end{array}$ & $\begin{array}{l}-0.1336^{* * *} \\
(0.0295)\end{array}$ \\
\hline & $\begin{array}{l}0.0967 * * * \\
(0.0363)\end{array}$ & $\begin{array}{l}0.0797 * * \\
(0.0317)\end{array}$ & $\begin{array}{l}0.0549 * * \\
(0.0229)\end{array}$ & $\begin{array}{l}0.0840^{* * *} \\
(0.0294)\end{array}$ \\
\hline $\begin{array}{l}0.3207 * * * \\
(0.0644)\end{array}$ & $\begin{array}{l}0.1781 * * * \\
(0.0361)\end{array}$ & $\begin{array}{l}0.5149 * * * \\
(0.0603)\end{array}$ & $\begin{array}{l}0.3909 * * * \\
(0.1278)\end{array}$ & $\begin{array}{l}0.2813 * * * \\
(0.0871)\end{array}$ \\
\hline 6367 & 3348 & 1677 & 827 & 415 \\
\hline
\end{tabular}

\begin{tabular}{|c|c|c|c|c|c|}
\hline $\begin{array}{c}\text { 2nd on } \\
\text { 1st Round }\end{array}$ & $\begin{array}{c}\text { 3rd on } \\
\text { 2nd Round }\end{array}$ & $\begin{array}{l}\text { Qfinals on } \\
\text { 3rd Round }\end{array}$ & $\begin{array}{c}\text { Sfinals on } \\
\text { Qfinals }\end{array}$ & $\begin{array}{c}\text { Final on } \\
\text { Sfinals } \\
\end{array}$ & $\begin{array}{c}\text { The Final } \\
\text { (no shadow) }\end{array}$ \\
\hline \multirow[t]{3}{*}{$\begin{array}{l}0.0742 * * * \\
(0.0124)\end{array}$} & $\begin{array}{l}0.0802 * * * \\
(0.0157)\end{array}$ & $\begin{array}{l}0.0741 * * * \\
(0.0208)\end{array}$ & $\begin{array}{l}0.0879 * * \\
(0.0365)\end{array}$ & $\begin{array}{l}0.1833 * * \\
(0.0715)\end{array}$ & \\
\hline & $\begin{array}{l}-0.3119 * * * \\
(0.0386)\end{array}$ & $\begin{array}{l}-0.3448 * * * \\
(0.0381)\end{array}$ & $\begin{array}{l}-0.4260 * * * \\
(0.0472)\end{array}$ & $\begin{array}{l}-0.1285 * * * \\
(0.0267)\end{array}$ & $\begin{array}{l}-0.1228 * * * \\
(0.0359)\end{array}$ \\
\hline & $\begin{array}{l}0.1477 * * * \\
(0.0477)\end{array}$ & $\begin{array}{l}0.0869 * * \\
(0.0367)\end{array}$ & $\begin{array}{l}0.0971 * * \\
(0.0438)\end{array}$ & $\begin{array}{l}0.0679 * * * \\
(0.0202)\end{array}$ & $\begin{array}{l}0.0592 * * \\
(0.0254)\end{array}$ \\
\hline $\begin{array}{l}0.2898^{* * *} \\
(0.0897)\end{array}$ & $\begin{array}{l}0.2365^{* * *} \\
(0.0626)\end{array}$ & $\begin{array}{l}0.2590^{* * *} \\
(0.0716)\end{array}$ & $\begin{array}{l}0.0513 * * \\
(0.0256)\end{array}$ & $\begin{array}{l}0.4787 * * * \\
(0.0796)\end{array}$ & $\begin{array}{l}0.6922^{* * *} \\
(0.1118)\end{array}$ \\
\hline 2825 & 1996 & 1006 & 506 & 253 & 125 \\
\hline
\end{tabular}

\begin{tabular}{|c|c|c|c|c|c|c|}
\hline $\begin{array}{c}\text { 2nd on } \\
\text { 1st Round }\end{array}$ & $\begin{array}{c}\text { 3rd on } \\
\text { 2nd Round }\end{array}$ & $\begin{array}{c}\text { 4th on } \\
\text { 3rd Round }\end{array}$ & $\begin{array}{l}\text { Qfinals on } \\
\text { 4th Round }\end{array}$ & $\begin{array}{c}\text { Sfinals on } \\
\text { Qfinals }\end{array}$ & $\begin{array}{c}\text { Final on } \\
\text { Sfinals }\end{array}$ & $\begin{array}{c}\text { The Final } \\
\text { (no shadow) }\end{array}$ \\
\hline \multirow[t]{3}{*}{$\begin{array}{l}0.1766^{* * *} \\
(0.0114)\end{array}$} & $\begin{array}{l}0.1090^{* * *} \\
(0.0170)\end{array}$ & $\begin{array}{l}0.0763 * * * \\
(0.0289)\end{array}$ & $\begin{array}{l}0.0983 \\
(0.0620)\end{array}$ & $\begin{array}{l}-0.0158 \\
(0.0888)\end{array}$ & $\begin{array}{l}-0.2772 \\
(0.2888)\end{array}$ & \\
\hline & $\begin{array}{l}-0.3656^{* * *} \\
(0.0493)\end{array}$ & $\begin{array}{l}-0.3593 * * * \\
(0.0427)\end{array}$ & $\begin{array}{l}-0.2512 * * * \\
(0.0656)\end{array}$ & $\begin{array}{l}-0.2810^{* * *} \\
(0.0438)\end{array}$ & $\begin{array}{l}-0.0821 * * * \\
(0.0152)\end{array}$ & $\begin{array}{l}-0.0402 \\
(0.0304)\end{array}$ \\
\hline & $\begin{array}{l}0.1063 * * * \\
(0.0375)\end{array}$ & $\begin{array}{l}0.0831 * * \\
(0.0348)\end{array}$ & $\begin{array}{l}0.0788 * * \\
(0.0364)\end{array}$ & $\begin{array}{l}0.0190 \\
(0.0510)\end{array}$ & $\begin{array}{l}0.0041 \\
(0.0134)\end{array}$ & $\begin{array}{l}0.0303 \\
(0.0325)\end{array}$ \\
\hline $\begin{array}{l}0.0714 * * * \\
(0.0262)\end{array}$ & $\begin{array}{l}0.2615^{* * *} \\
(0.0292)\end{array}$ & $\begin{array}{l}0.3206^{* * *} \\
(0.0644)\end{array}$ & $\begin{array}{l}0.3192 * * * \\
(0.0691)\end{array}$ & $\begin{array}{l}0.3802 * * * \\
(0.1140)\end{array}$ & $\begin{array}{l}0.3747 * * * \\
(0.0785)\end{array}$ & $\begin{array}{l}0.4984 * * * \\
(0.1601)\end{array}$ \\
\hline 2791 & 1706 & 847 & 431 & 214 & 106 & 53 \\
\hline
\end{tabular}

Notes: Values in parentheses are robust standard errors. All regressions include tournament-level fixed effects. Column labels identify the round and the shadow effect being analyzed. For example, "2nd on 1st Round" uses match observations from the first round of a tournament and considers the shadow of the expected second round opponent on first round outcomes.

$* p<0.10, * * p<0.05, * * * p<0.01$ 
Figure A1: Example Densities of Joint Noise - Normal Distribution

Panel 1: Return to Effort as a Function of Different "Noise Levels"

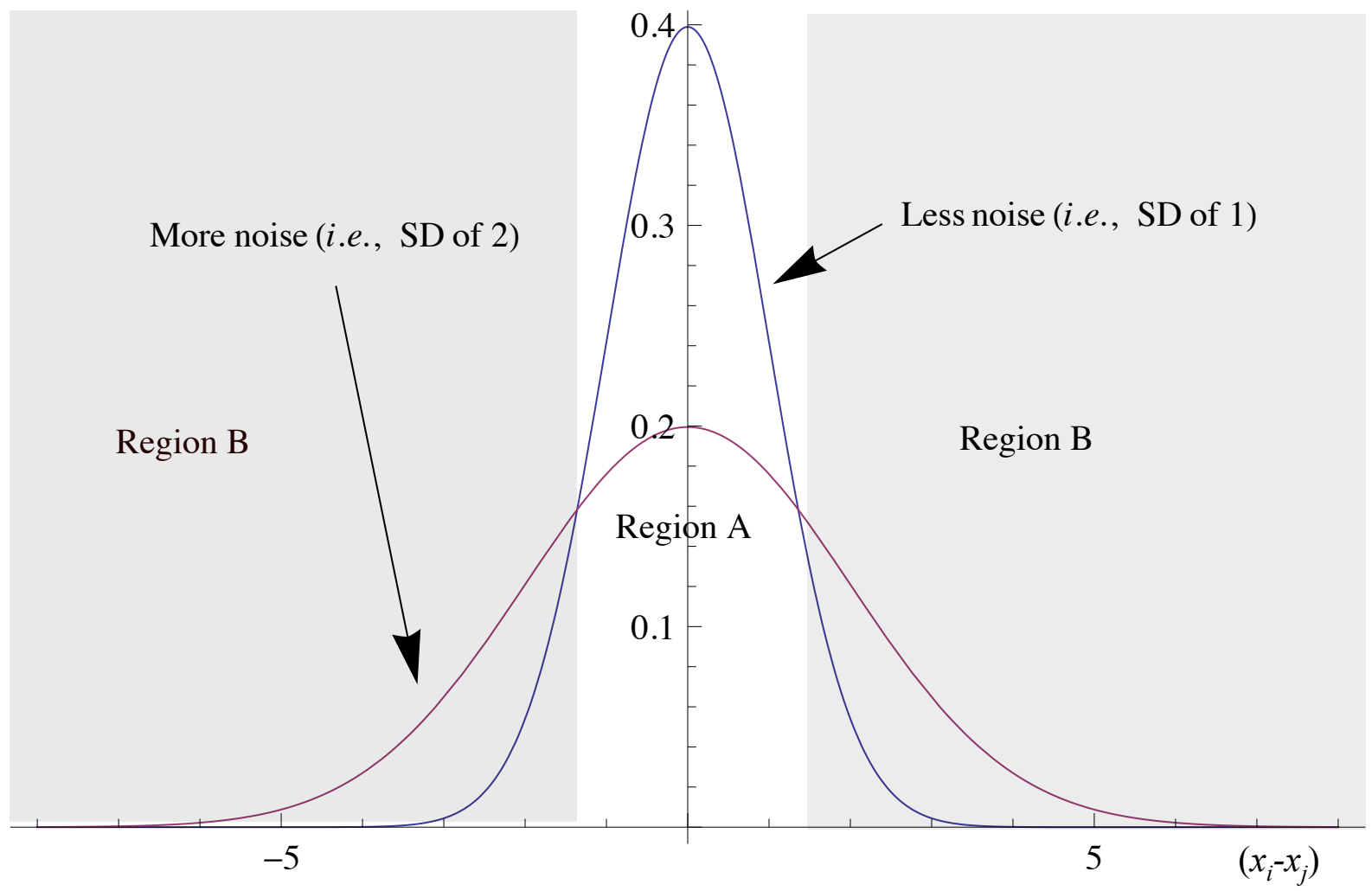

Panel 2: Normal Distribution of Joint Noise

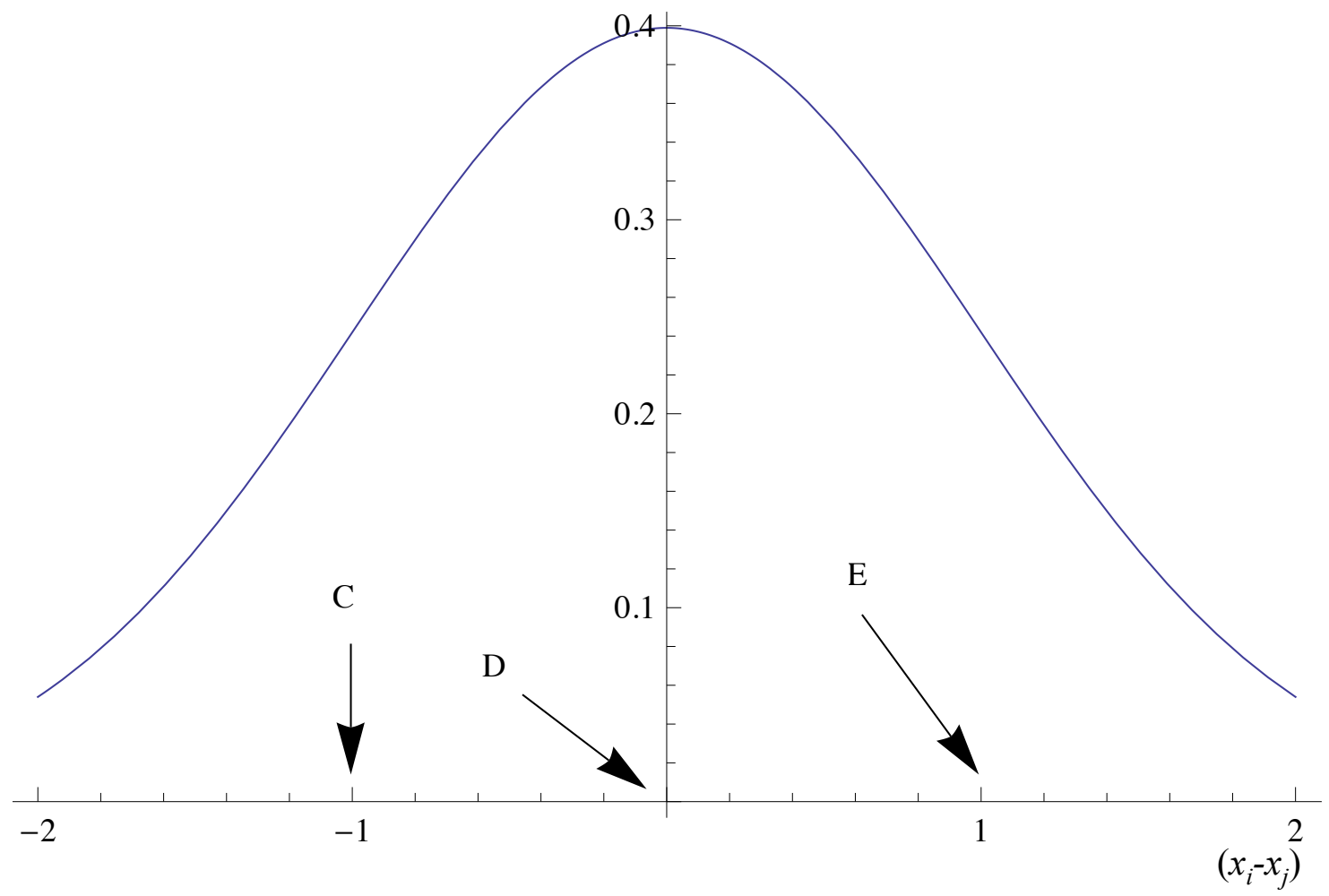


$\underline{\text { Table A1 - Probit Coefficients for Spillover and Shadow Effects }}$

Dependent Variable:

Five Round Events

Expected Future

Opponent Rank

Stronger Player's

Previous Games

Weaker Player's

Previous Games

Current Rank Ratio

(Worse / Better Rank)

\# of observations

Six Round Events

Expected Future

Opponent Rank

Stronger Player's

Previous Games

Weaker Player's

Previous Games

Current Rank Ratio

(Worse / Better Rank)

\# of observations

Seven Round Events

Expected Future

Opponent Rank

Stronger Player's

Previous Games

Weaker Player's

Previous Games

Current Rank Ratio

(Worse / Better Rank)

\# of observations

Stronger Player Wins in Current Period (0\% or 100\%)

\begin{tabular}{|c|c|c|c|c|}
\hline $\begin{array}{l}\text { 2nd on } \\
\text { 1st Round }\end{array}$ & $\begin{array}{l}\text { Qfinals on } \\
\text { 2nd Round }\end{array}$ & $\begin{array}{c}\text { Sfinals on } \\
\text { Qfinals }\end{array}$ & $\begin{array}{c}\text { Final on } \\
\text { Sfinals }\end{array}$ & $\begin{array}{l}\text { The Final } \\
\text { (no shadow) }\end{array}$ \\
\hline \multirow[t]{3}{*}{$\begin{array}{l}0.0014 * * * \\
(0.0004)\end{array}$} & $\begin{array}{l}0.0023 * * * \\
(0.0008)\end{array}$ & $\begin{array}{l}0.0015 \\
(0.0013)\end{array}$ & $\begin{array}{l}0.0016 \\
(0.0018)\end{array}$ & \\
\hline & $\begin{array}{l}-0.0118^{* * *} \\
(0.0034)\end{array}$ & $\begin{array}{l}-0.0065^{*} \\
(0.0034)\end{array}$ & $\begin{array}{l}-0.0034 \\
(0.0024)\end{array}$ & $\begin{array}{l}-0.0083 * * \\
(0.0033)\end{array}$ \\
\hline & $\begin{array}{l}0.002 \\
(0.0036)\end{array}$ & $\begin{array}{l}0.0039 \\
(0.0035)\end{array}$ & $\begin{array}{l}0.0039 \\
(0.0025)\end{array}$ & $\begin{array}{l}0.0051 \\
(0.0034)\end{array}$ \\
\hline $\begin{array}{l}0.0214 * * * \\
(0.0044)\end{array}$ & $\begin{array}{l}0.0136^{*} \\
(0.0076)\end{array}$ & $\begin{array}{l}0.0095^{* *} \\
(0.0046)\end{array}$ & $\begin{array}{l}0.0470^{* * *} \\
(0.0103)\end{array}$ & $\begin{array}{l}0.0054 \\
(0.0075)\end{array}$ \\
\hline 6749 & 3435 & 1718 & 856 & 432 \\
\hline
\end{tabular}

\begin{tabular}{|c|c|c|c|c|c|}
\hline $\begin{array}{c}\text { 2nd on } \\
\text { 1st Round }\end{array}$ & $\begin{array}{c}\text { 3rd on } \\
\text { 2nd Round }\end{array}$ & $\begin{array}{l}\text { Qfinals on } \\
\text { 3rd Round }\end{array}$ & $\begin{array}{c}\text { Sfinals on } \\
\text { Qfinals }\end{array}$ & $\begin{array}{c}\text { Final on } \\
\text { Sfinals }\end{array}$ & $\begin{array}{c}\text { The Final } \\
\text { (no shadow) }\end{array}$ \\
\hline \multirow[t]{3}{*}{$\begin{array}{l}0.0008 \\
(0.0008)\end{array}$} & $\begin{array}{l}0.0013 \\
(0.0014)\end{array}$ & $\begin{array}{l}0.0036^{*} \\
(0.0021)\end{array}$ & $\begin{array}{l}0.0016 \\
(0.0033)\end{array}$ & $\begin{array}{l}0.0061 \\
(0.0076)\end{array}$ & \\
\hline & $\begin{array}{l}-0.0029 \\
(0.0035)\end{array}$ & $\begin{array}{l}-0.0082 * * \\
(0.0037)\end{array}$ & $\begin{array}{l}-0.0150 * * * \\
(0.0045)\end{array}$ & $\begin{array}{l}-0.0076^{* * *} \\
(0.0025)\end{array}$ & $\begin{array}{l}-0.0009 \\
(0.0033)\end{array}$ \\
\hline & $\begin{array}{l}0.0086^{* *} \\
(0.0044)\end{array}$ & $\begin{array}{l}0.0025 \\
(0.0037)\end{array}$ & $\begin{array}{l}0.0089^{* *} \\
(0.0045)\end{array}$ & $\begin{array}{l}0.0031 \\
(0.0021)\end{array}$ & $\begin{array}{l}0.0007 \\
(0.0027)\end{array}$ \\
\hline $\begin{array}{l}0.0197 * * * \\
(0.0049)\end{array}$ & $\begin{array}{l}0.0267 * * * \\
(0.0043)\end{array}$ & $\begin{array}{l}0.0270 * * * \\
(0.0072)\end{array}$ & $\begin{array}{l}0.0076 \\
(0.0078)\end{array}$ & $\begin{array}{l}0.0306^{*} \\
(0.0170)\end{array}$ & $\begin{array}{l}0.0494 \\
(0.0336)\end{array}$ \\
\hline 2923 & 2043 & 1029 & 516 & 256 & 129 \\
\hline
\end{tabular}

\begin{tabular}{|c|c|c|c|c|c|c|}
\hline $\begin{array}{l}\text { 2nd on } \\
\text { 1st Round }\end{array}$ & $\begin{array}{c}\text { 3rd on } \\
\text { 2nd Round }\end{array}$ & $\begin{array}{c}\text { 4th on } \\
\text { 3rd Round }\end{array}$ & $\begin{array}{l}\text { Qfinals on } \\
\text { 4th Round }\end{array}$ & $\begin{array}{c}\text { Sfinals on } \\
\text { Qfinals }\end{array}$ & $\begin{array}{c}\text { Final on } \\
\text { Sfinals }\end{array}$ & $\begin{array}{l}\text { The Final } \\
\text { (no shadow) }\end{array}$ \\
\hline \multirow[t]{3}{*}{$\begin{array}{l}0.0036^{* * *} \\
(0.0009)\end{array}$} & $\begin{array}{l}0.0029 * \\
(0.0017)\end{array}$ & $\begin{array}{l}0.0046 * \\
(0.0025)\end{array}$ & $\begin{array}{l}0.0133 * * \\
(0.0057)\end{array}$ & $\begin{array}{l}0.0026 \\
(0.0094)\end{array}$ & $\begin{array}{l}0.0038 \\
(0.0215)\end{array}$ & \\
\hline & $\begin{array}{l}-0.0172 * * * \\
(0.0043)\end{array}$ & $\begin{array}{l}-0.0123 * * * \\
(0.0039)\end{array}$ & $\begin{array}{l}-0.0065 \\
(0.0046)\end{array}$ & $\begin{array}{l}-0.0069 \\
(0.0049)\end{array}$ & $\begin{array}{l}-0.0037^{* *} \\
(0.0018)\end{array}$ & $\begin{array}{l}-0.003 \\
(0.0033)\end{array}$ \\
\hline & $\begin{array}{l}0.006 \\
(0.0037)\end{array}$ & $\begin{array}{l}0.0034 \\
(0.0034)\end{array}$ & $\begin{array}{l}0.0034 \\
(0.0035)\end{array}$ & $\begin{array}{l}-0.0019 \\
(0.0049)\end{array}$ & $\begin{array}{l}0.001 \\
(0.0016)\end{array}$ & $\begin{array}{l}0.0024 \\
(0.0031)\end{array}$ \\
\hline $\begin{array}{l}0.0355^{* * *} \\
(0.0096)\end{array}$ & $\begin{array}{l}0.0160^{* * *} \\
(0.0053)\end{array}$ & $\begin{array}{l}0.0301 * * * \\
(0.0063)\end{array}$ & $\begin{array}{l}0.0247 * * * \\
(0.0088)\end{array}$ & $\begin{array}{l}0.0107 \\
(0.0120)\end{array}$ & $\begin{array}{l}0.0008 \\
(0.0098)\end{array}$ & $\begin{array}{l}0.1644 * * * \\
(0.0550)\end{array}$ \\
\hline 2903 & 1716 & 858 & 432 & 216 & 108 & 54 \\
\hline
\end{tabular}

Notes: Please note that the table reports coefficient estimates, not marginal effects. Values in parentheses are robust standard errors. All regressions include tournament-level fixed effects. Column labels identify the round and the shadow effect being analyzed. For example, "2nd on 1st Round" uses match observations from the first round of a tournament and considers the shadow of the expected second round opponent on first round outcomes.

${ }^{*} p<0.10,{ }^{* *} p<0.05, * * * p<0.01$ 